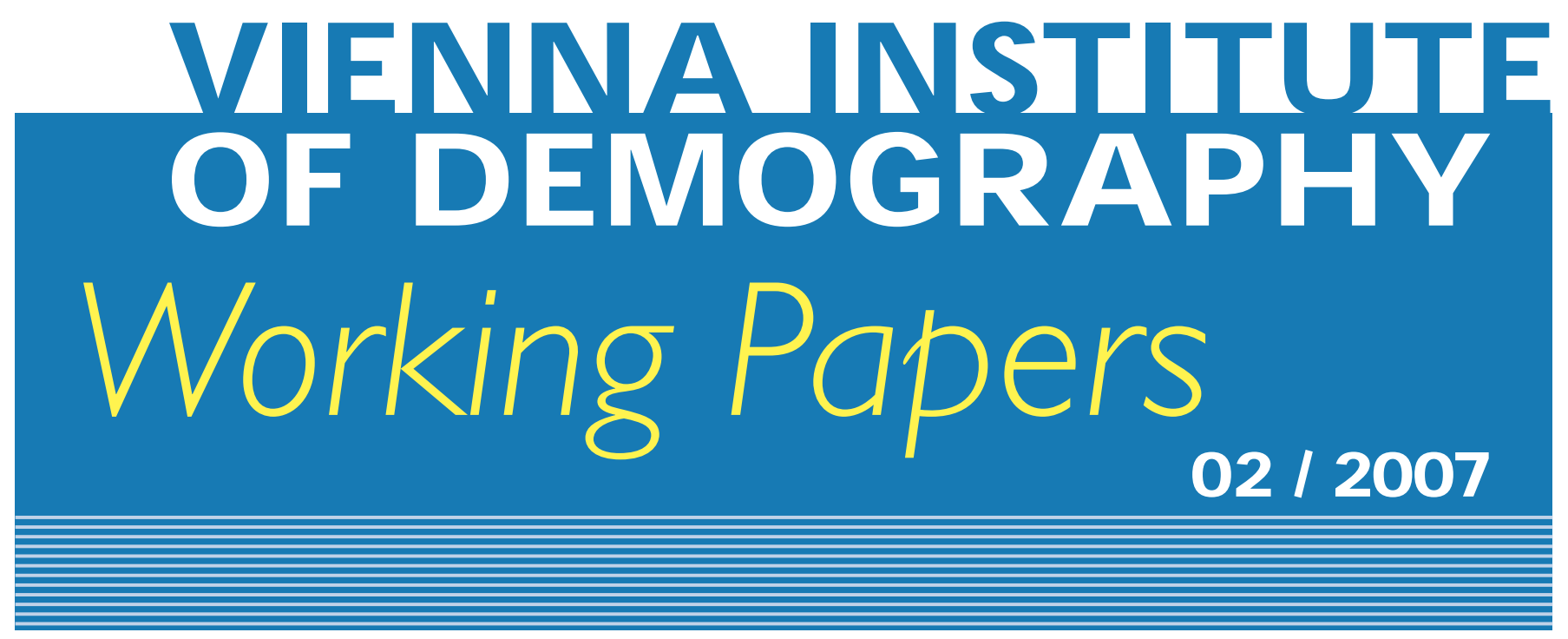

Gustav Feichtinger, M aria W inkler-Dworak, Inga Freund, and Alexia Prskawetz

\title{
O $n$ the Age Dynamics of Learned Societies: Taking the Example of the Austrian Academy of Sciences
}

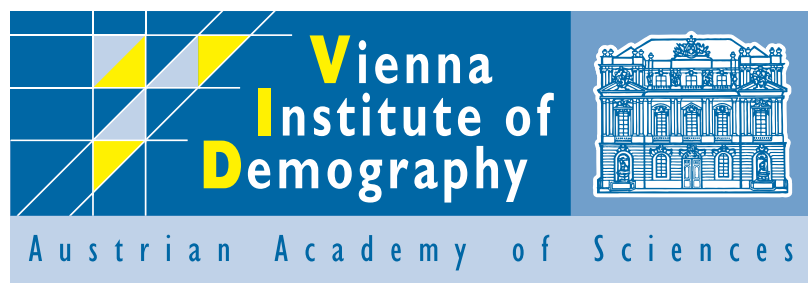

Vienna Institute of D emography Austrian A cademy of Sciences

Prinz Eugen-Straße 8-10 · A-1040 Vienna · A ustria

E-Mail: vid@ oeaw.ac.at

W ebsite: www.oeaw.ac.at/vid 


\begin{abstract}
In a hierarchical organisation of stable size the annual intake is strictly determined by the number of deaths and a statutory retirement age (if there is one). In this paper we reconstruct the population of the Austrian Academy of Sciences from 1847 to 2005. For the Austrian Academy of Sciences we observe a shift of its age distribution towards older ages, which is due to rising life expectancy, i.e. a rising age at death, on the one hand as well as an increased age at entry on the other hand. Therefore the number of new entrants has been fluctuating considerably-especially reflecting some statutory changes-and the length of tenure before reaching the statutory retirement age has declined during the second half of the last century. Based on alternative scenarios of the age distribution of incoming members-including a young, an old, the 'current' and a mixed-age model—we then project the population of the Austrian Academy and its ageing forward in time. Our results indicate that the 'optimum policy' would be to elect either young or old aged new members.
\end{abstract}

\title{
Keywords
}

Learned societies, age-structured dynamic models, optimal control.

\section{Authors}

Gustav Feichtinger is Professor for Operations Research at the Vienna University of Technology, Institute for Mathematical Methods in Economics, Research Unit ORDYS and Senior Scholar at the Vienna Institute of Demography of the Austrian Academy of Sciences, Vienna, Austria.

Maria Winkler-Dworak is a Research Scientist at the Vienna Institute of Demography of the Austrian Academy of Sciences, Vienna, Austria.

Inga Freund a Research Scientist at the Vienna Institute of Demography of the Austrian Academy of Sciences, Vienna, Austria.

Alexia Prskawetz is a Senior Scholar at the Vienna Institute of Demography of the Austrian Academy of Sciences, Vienna, Austria, and a Research Associate at the Institute for Social and Economic Research at University Essex, Colchester, U.K.

\section{Acknowledgements}

We are thankful for valuable comments and constructive support to (in alphabetical order) Christian Balluch, wM Gerhart Bruckmann, Ernö Déak, wM Egbert Dierker, Richard Gisser, Birgit Heider, Frank Kolesnik, Elisabeth Lebensaft, wM Elisabeth Lichtenberger, wM Herbert Mang, wM Herbert Matis, Robert Püringer, Leonhard Reis, Tanja Schumi, Stefan Sienell, and Peter Urbanitsch. 


\title{
On the Age Dynamics of Learned Societies-Taking the Example of the Austrian Academy of Sciences
}

\author{
Gustav Feichtinger, Maria Winkler-Dworak, Inga Freund, Alexia Prskawetz
}

\section{Introduction}

For some time now, a key issue of scientific research, politics and the media has been the ever-increasing age of the population. This increase is due both to declining birth rates and the rising life expectation, i.e., to diminishing mortality-specifically in the older age groups. To counteract this trend in the general ageing of the population, policy makers have the possibility to intervene by introducing measures to encourage childbearing or migration. In cases where a population is closed to migration and where early death can be ruled out in the usual course of events, the logic of population dynamics implies that the only alternatives are growing and/or ageing. With the finite space on our planet prohibiting continuous population growth, a continuing trend towards top-heavy age pyramids is unavoidable, as shown in Figure 1 for the Austrian population.

Figure 1: Population pyramids for the years 1900 and 2000 and a projected pyramid graph for 2050
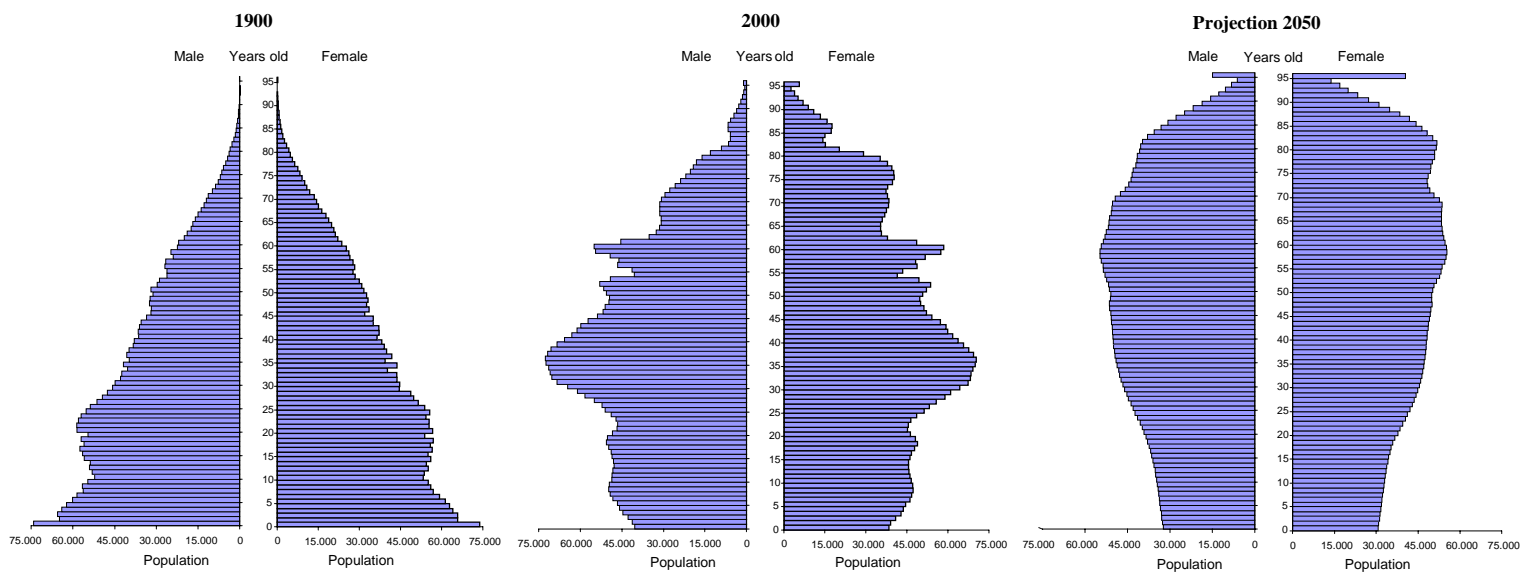

Source: Statistics Austria.

However, this raises a number of economic, fiscal and sociopolitical questions: Is an ageing population just as productive as a young population? How can pension systems retain their financial sustainability when people spend a steadily increasing part of their lifetime outside their economic activity? Can an older population "remain on the pulse of time”?

So we just have to live in an ageing population, and the subpopulations of learned societies are no exceptions to this rule. With regard to the Austrian Academy of Sciences (Österreichische Akademie der Wissenschaften/ÖAW), we have to take into account the restrictive particularity that here the maximum number of members below a certain age threshold is limited. This automatically restricts the influence of the younger cohorts' age. 
What options does an Academy have to respond to the increased ageing of its member structure? Should it perhaps not respond at all to this development, as it is a mere reflection of the progressive ageing of our society?

What constituted the point of departure of our paper was a number of studies on the “Académie des Sciences (Institut de France)” (Leridon 2004), the "Royal Danish Academy of Sciences and Letters" (Matthiessen 1999) and the "National Academy of Sciences" [of the USA] (Cohen 2003). These studies also examined the subject of learned societies by analysing their historic, present and future demographic development-in particular in the context of increased ageing and declining mortality.

The following investigations shall provide answers to the above questions. After a few formal comments concerning the reconstruction of the data we first look into the historical developments. Chapter 2 is dedicated to full Academy members, ${ }^{1}$ compiling a number of descriptive statistics and illustrations on their development as to numbers, structures and age since the foundation of the Academy. They refer-if not otherwise defined - to the number and age of the full members of both Academy sections, i.e., the Section for Mathematics and the Natural Sciences and the Section for the Humanities and the Social Sciences, represented over time (by 1 July of each year). Here we consider both the group of existing members and that of new entrants as well as the transition from corresponding to full membership, before we go into the mortality of Academy members as mentioned above. A scenario of possible future trends in the development of membership structure is presented in Chapter 3. Here we show several alternative projections that-based on the specific assumptions-yield potential combinations of the total size, age structure and new members of the Academy. Before we conclude (in Chapter 5) we would like to communicate an intuition, in Chapter 4, of a mathematical model that would cast the decision problem of the Academy in concrete terms and could be a basis for controlling measures. We are looking to find a compromise between the "optimum" age structure of the Academy population or its newly elected members and the highest possible number of new members per year.

We would like to describe and explain the historic situation within the demographic context and also assess future development including their potential bandwidth, pointing out possible disadvantageous trends and advising towards desired developments (demography as an aid in decision-making). However, if these developments are not compatible with exogenously predetermined objectives, the decision-making body-in this case the Academy in its entirety-is at least provided with a possibility to take corrective action.

\footnotetext{
${ }^{1}$ See Chapter 2.1 for a detailed description of member categories. As only full members hold the right to vote, they have a considerable shaping effect on the Academy's population structure.
} 


\section{Demographic Evolution of the Austrian Academy of Sciences 1847- 2005}

\subsection{Reconstructing the Data}

The data come from the biographic records of the members of the Austrian Academy of Sciences (Hittmair and Hunger 1997). The Austrian Academy of Sciences was founded in 1847 as the 'Kaiserliche Akademie der Wissenschaften in Wien' under the auspices of emperor Ferdinand I. The Academy is structured around two sections (termed "Klassen" in German) - the Section for Mathematics and the Natural Sciences (math.nat.) and the Section for the Humanities and the Social Sciences (in German "philosophisch-historische Klasse”, phil.hist.). Membership distinguishes between honorary members, full members and corresponding members. The latter category further distinguishes between corresponding members residing in Austria and corresponding members abroad. Full membership requires residence in Austria. If a full member moves abroad, his or her status changes to that of a corresponding member abroad while living outside of Austria.

As an example for multiple status change, the case of Ludwig Boltzmann (Jahn 2001) is shown in Figure 2.

Ludwig Eduard Boltzmann was elected a corresponding member of the Austrian Academy of Sciences in 1874, while he was working as ordinarius (full professor) of Mathematics at the University of Vienna (187376). In 1876 he moved to the University of Graz where he headed the Institute of Physics and in 1885 he was elected as a full member of the Austrian Academy of Sciences. When he left Graz in order to teach at the Institute of Theoretical Physics in Munich in 1891, his status was changed to that of a corresponding member abroad. In 1895 he returned to the University of Vienna implying a change in membership status back to a full member. The following stay abroad in Leipzig (1900-1902) again entailed a change in membership status to corresponding member abroad. Back in Vienna, Boltzmann's membership status changed to corresponding member in 1902 and only in 1904 again to full member. (Remark: Apparently after his return to Vienna in 1902 there was no vacancy among the full members for some time.)

Figure 2: Status change illustrated through the example of Ludwig Eduard Boltzmann

Ludwig Eduard Boltzmann (20 Feb.1844 - 5 Sept.1906)

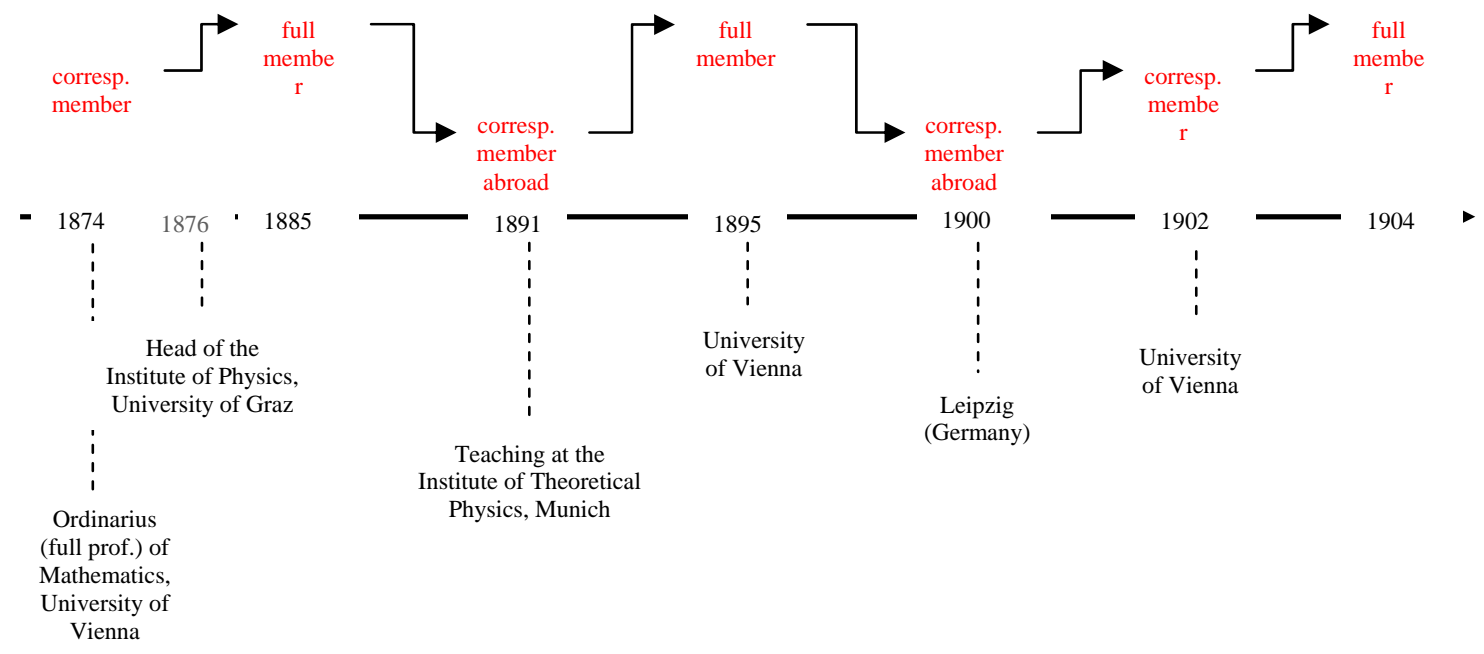


The biographic records include date of birth and death, year of election, section membership, membership status and year of change of membership status. Exits from the Academy were mainly through death with few exceptions. Four full members, two corresponding members, and one corresponding member abroad voluntarily resigned from the Academy. During the Nazi period, several Jewish members were excluded from the Academy: between autumn 1938 and autumn 1940, six full members and 15 corresponding members (including corresponding members abroad) were expelled on 'racial' grounds (Matis 1997). After the end of World War II, the excluded members were listed again in the membership directories. Nowadays membership directories do not mention those exclusions. When reconstructing the member populations during that time, we decided to keep these excluded members in the Academy population because we did not want to replicate the injustice committed at the time.

In 1945 those members of the Academy who had joined the NSDAP were suspended. With the Amnesty Law of 1948, however, the membership of almost all of them was restored again. Nowadays membership directories do not give any information about these suspensions either. ${ }^{2}$

Table 1: Changes in the byelaws concerning the number of members per section, age limits and rules of elections and the year they became operative.

\begin{tabular}{|c|c|c|c|}
\hline Byelaws & Year $^{\text {a }}$ & $\begin{array}{l}\text { Members } \\
\text { per section }\end{array}$ & Specific rules \\
\hline Statutes, $1^{\text {st }}$ version (1847) & 1847 & 24 & 24 members per section \\
\hline - Addendum (1848) & 1848 & 30 & Increase by 6 members per section \\
\hline \multicolumn{4}{|l|}{ Byelaws, $1^{\text {st }}$ version (1922) } \\
\hline - Addendum (1925) & 1925 & 33 & Increase by 3 members per section \\
\hline \multicolumn{4}{|l|}{ Byelaws, $3^{\text {rd }}$ version (1946) } \\
\hline - Addendum (1949) & 1950 & 33 & $\begin{array}{l}\text { Age limit of } 75 \text { years (see text for details), } \\
\text { maximum of five new members elected per } \\
\text { year }\end{array}$ \\
\hline - Addendum (1960) & 1961 & 33 & Restriction on elections dropped \\
\hline - Addendum (1971) & 1972 & 33 & Age limit of 70 years (see text for details) \\
\hline - Addendum (1991) & 1992 & $45^{\mathrm{b}}$ & Increase by 12 members per section \\
\hline
\end{tabular}

For the purposes of reconstructing the membership population, we assumed that elections always took place in mid-May each year, which has been the case at least in recent years. If members moved abroad or returned to Austria, we coded the change in membership status to take place in the middle of the year due to lack of information on the actual month of change.

\footnotetext{
2 A thorough description of the activities of the Austrian Academy of Sciences from 1938-1945 can be found in Matis (1997).
} 
In this way, it is possible to chronologically reconstruct in particular those changes of the Academy's statutes which led to new section sizes, age limits and rules of election. Table 1 summarises (the amendments of) the byelaws and gives the year in which the relevant change became effective. Apart from the increase of the maximum number of members in 1848, 1925 and 1992, age thresholds were introduced. From 1950 onwards, members who were older than 75 years, no longer counted for the computation of the maximum numbers while still keeping their full membership rights. This age threshold was lowered to 70 years in 1972 .

Below we will examine the population of the 'Austrian Academy of Sciences' in closer detail, particularly focusing on the full members. Since only these are vested with election rights, they may influence the current member structure by electing new members of a certain age group.

\subsection{Population Structure and Age Structure over Time}

Figure 3 shows the development of full members from 1847 to 2005. The years on which the amendments of the byelaws took place are marked. After a quite stable process in the first half of the Academy's existence, the above mentioned byelaw amendments led to a continuous rise in membership numbers. Besides the direct increases of the maximum number of members for each section in the years 1848, 1925 and 1992, the introduction of the 75-years age threshold in 1950 as well as its further reduction to 70 years in 1972 created a considerable space for potential members to be elected. This led to batch-wise growth of the population. Consequently, the Academy started with 39 full members in 1847 and grew to 167 full members in 2005. Among the 167 full members 88 full members belong to the "math.nat." section, whereas 79 are members of the "phil.hist." section.

Concerning the development of full members by gender over time, there were six full female members in 2005, among whom two belonged to the math.nat. and four to the phil.hist section. In 1973, Berta Karlik was elected as the first female full member into the math.nat. section and she remained the only woman in the math.nat. section until her death in 1990. It took until 2003 when another woman (Renée Schroeder) was elected in the math.nat. section. In 2005 the election of the second female member in the math.nat. section followed: Marjori Ann Matzke.

The first woman elected into the phil.hist. section was Margret Dietrich in 1981. Further female members in this section followed in 1987 (Elisabeth Lichtenberger), 1995 (Sigrid Jakoltzy-Deger), 1996 (Grete Walter-Klingenstein) and in 2001 (Herta Nagl).

A detailed picture of the age development over time is plotted in Figure 4, which contains the average age of full Academy members with and without consideration of the introduction of the age threshold of 75 years in 1950 and of its reduction to 70 years in 1972. Starting at 50 (math.nat. section) and 52 years (phil.hist. section) in 1849, the average age rose to 66 (math.nat. section) and 68 (phil.hist. section) years during a time span of one hundred years. With the introduction of the age threshold we see a split 
Figure 3: Number of full members by section, 1847-2005 (at mid-year)

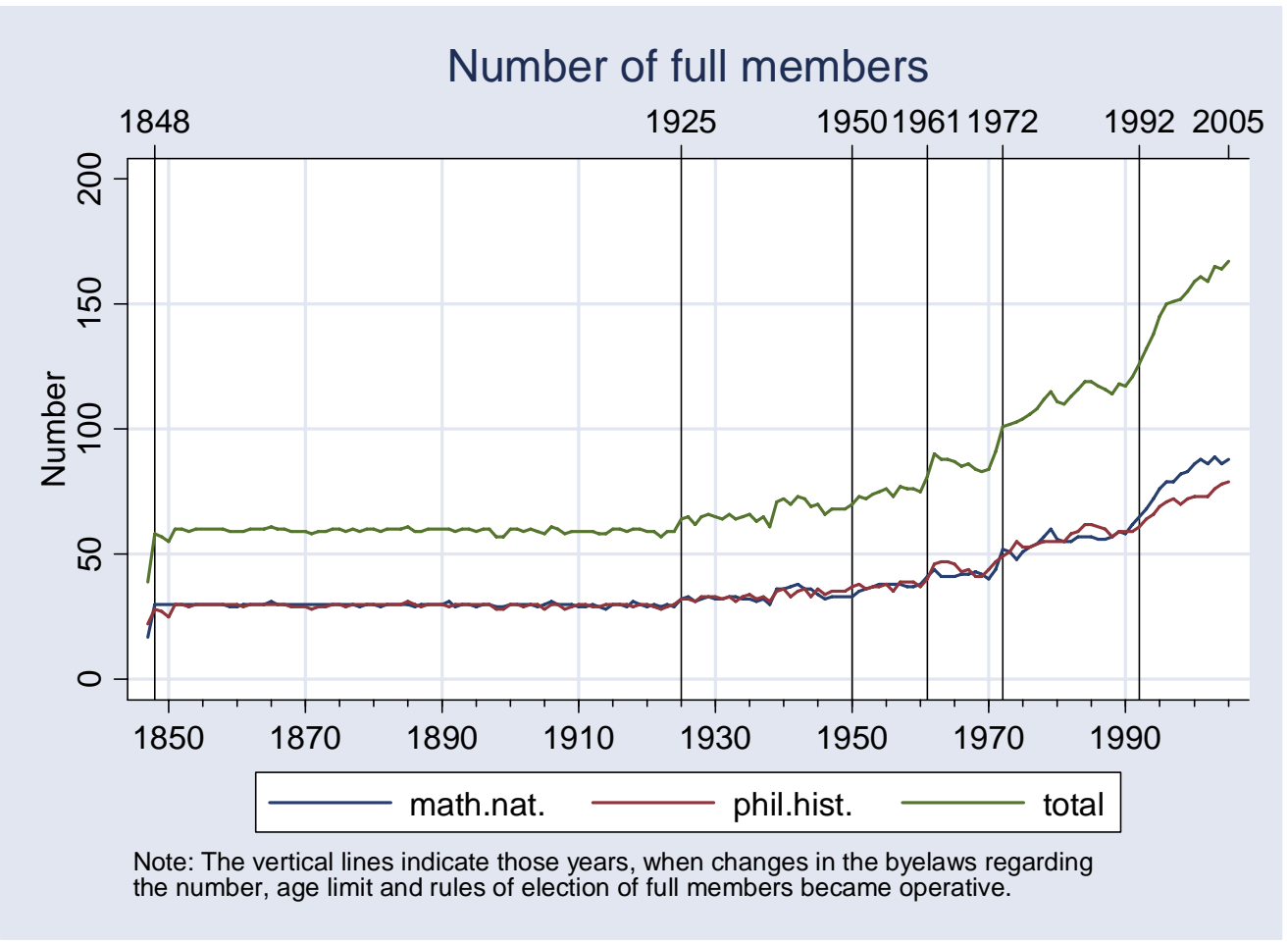

Figure 4: Mean age of full members per section over time (at mid-year).

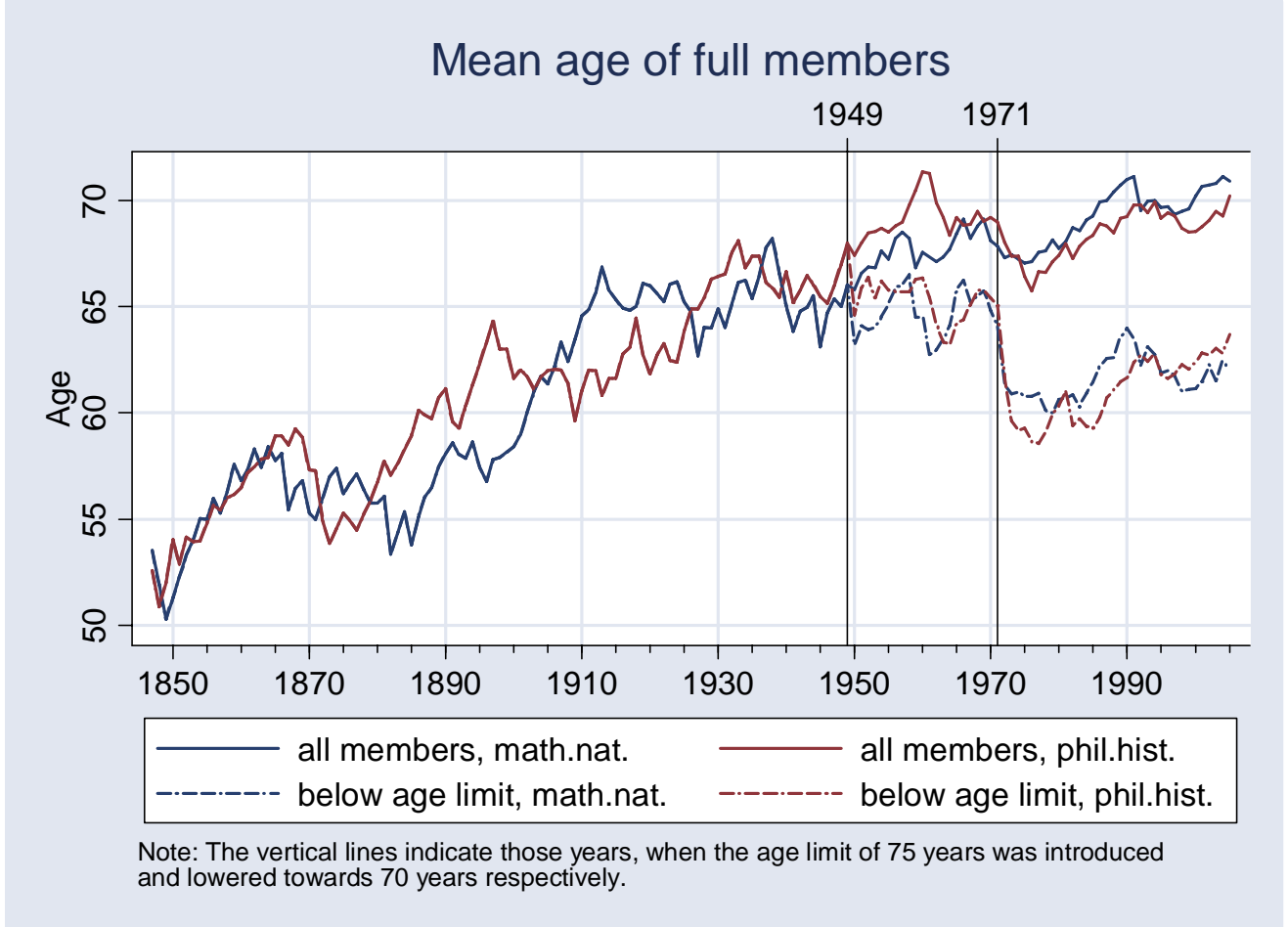


development: while the overall average age continues at a higher level compared to the average age of those full members below the threshold age, the latter experiences an additional impulse of rejuvenation due to the decreased age limit. In 2005, the average age in the math.nat. (phil.hist.) section was 71 (70) years, counting all members.

Focussing on broader age groups over time shows that the age group of the 60 to 69year olds dominates, while the 80+ group keeps increasing steadily, which is due to rising life expectancy and also to an increasing age at election (figure not shown).

The duration of membership as a full member (Figure 5) is determined by the entrance age on the one hand and by the time of death on the other. ${ }^{3}$ In spite of partly strong variations over time- - which are caused by the small sample size - the mean period spent in the population by full members fluctuates around a value of 20 years during the first half of the 20th century. Afterwards, it rose from 16 years in 1946-50 to the recent average of 27 years for all members, while the mean tenure of full members below the threshold age now lasts 12 years.

Figure 5: Average duration of full members by section at time of death or voluntary exit as well as at reaching the age limit of 75 and 70 years respectively, in 5-year periods

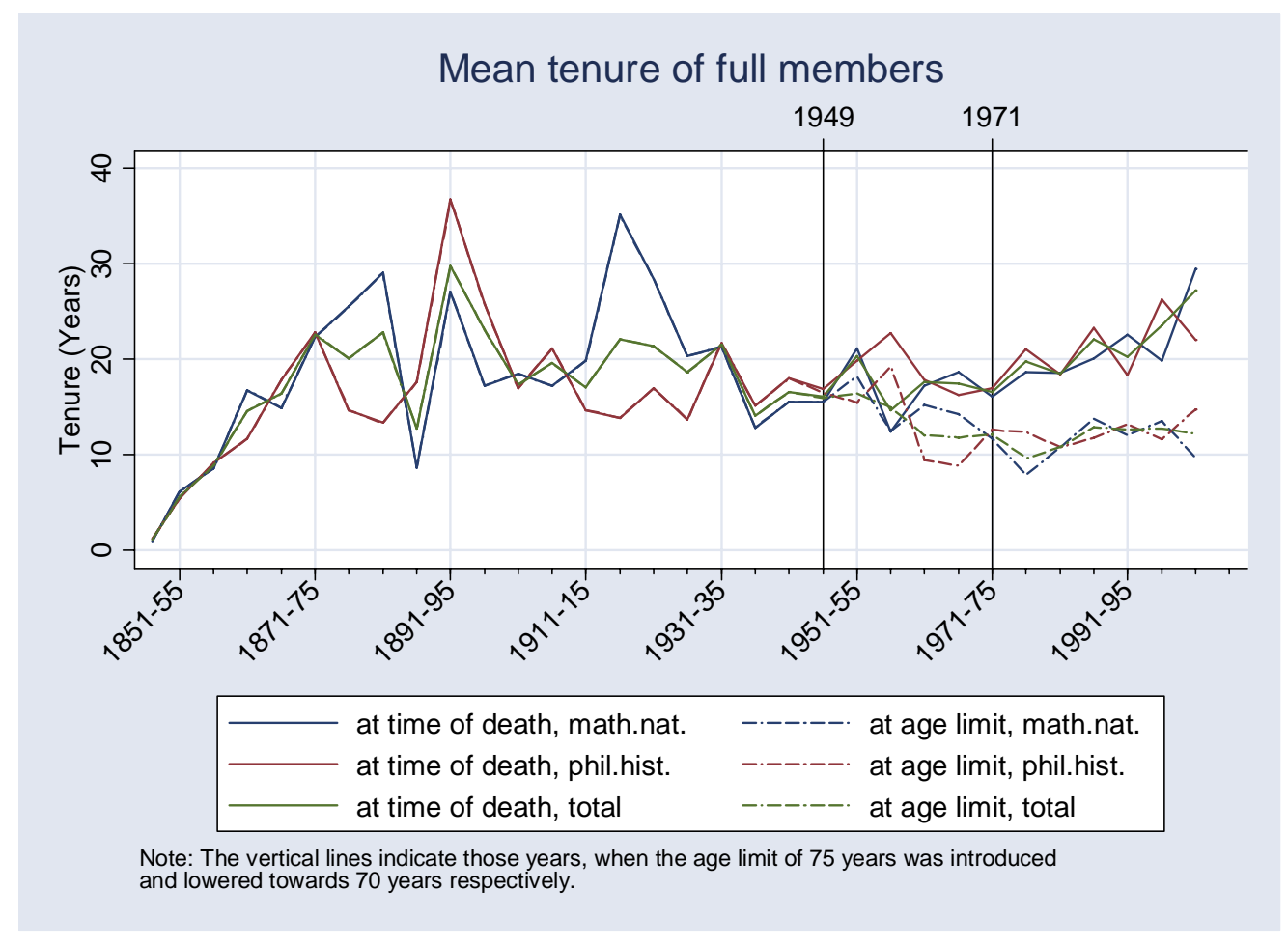
deaths.

In the following two sections we briefly review the dynamics of new entrants and

\footnotetext{
${ }^{3}$ In the history of the Austrian Academy of Sciences only seven members left the academy voluntarily.
} 


\subsection{New Entrants}

The number of elected members per section since the establishment of the Academy is represented in Figure 6. While the number of elected members for each 5-year period up to the beginning of the 20th century lay around 10-20 members, this number gradually rose to over 20-25 later on. Clear peaks show in particular the amendments of the byelaws around 1961, 1972 and 1992, when each time it became possible to elect a larger number of new members at a time. Hence, 23 new full members were elected during the years 1961-62, 13 new full members in 1972 and 43 new full members from 1992 to 1995.

Figure 6: Number of elected full members per section (5-year periods)

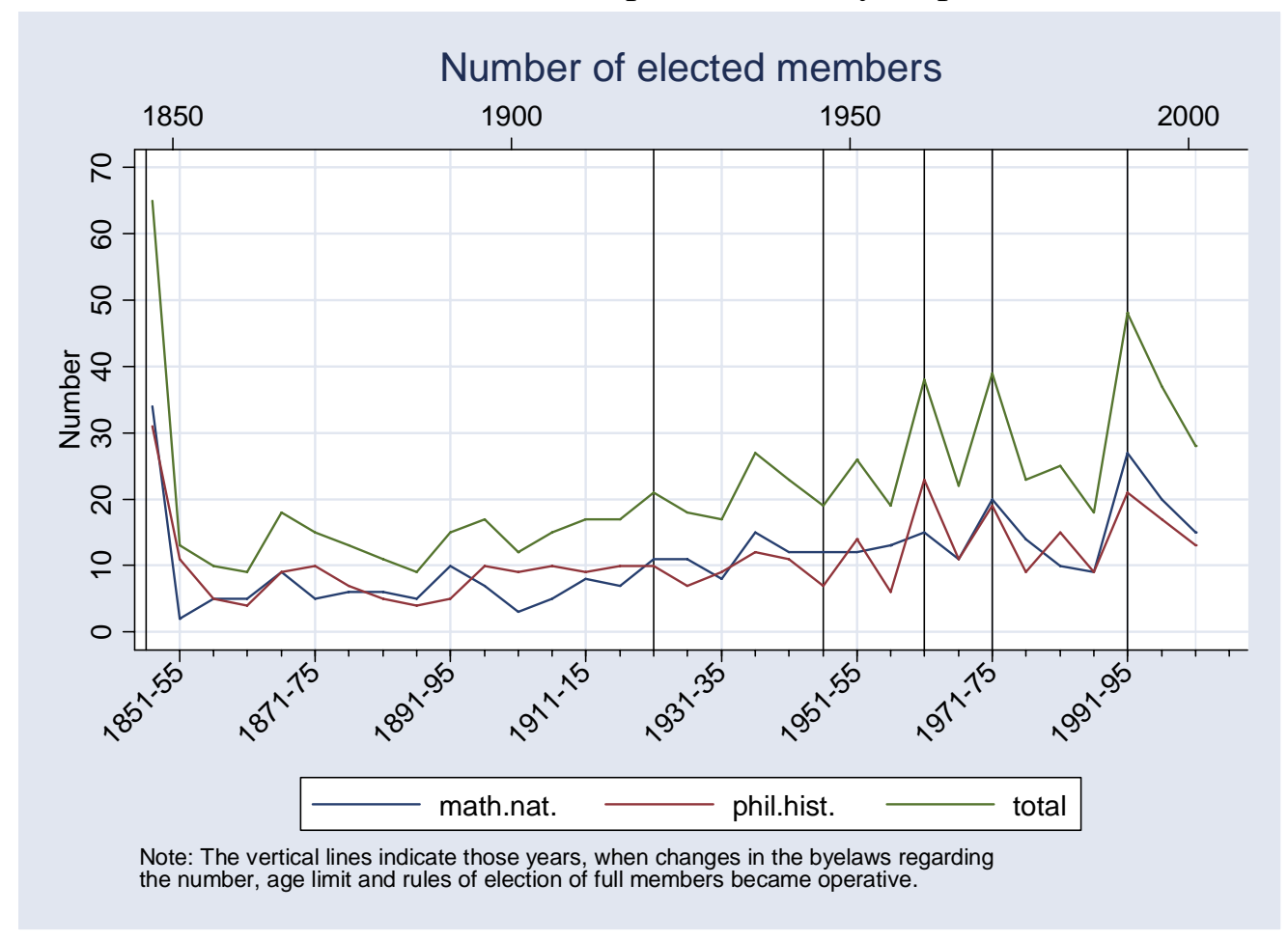

An illustration of the average age at the time of election is given in Figure 7. After its lowest value of about 40 years in 1861-65, the average age of elected full members rose continuously, exceeding age 60 several times in the second half of the 20th century. In the recent past it has decreased again due to the reduction in the threshold age that led to the election of younger members. 
Figure 7: Mean age of full members at time of election (5-year periods)

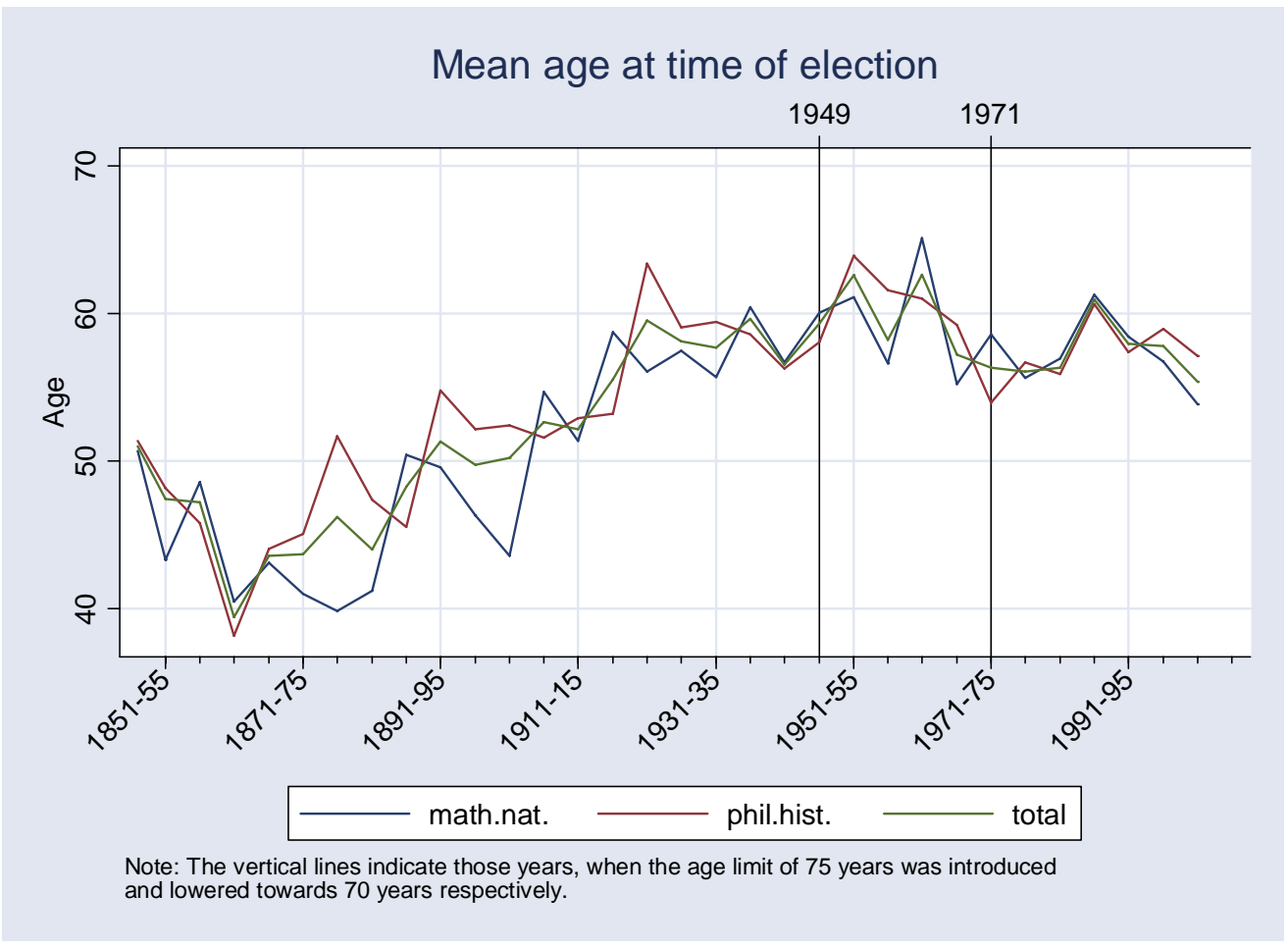

\subsection{Transition from Corresponding to Full Member}

Figure 8 offers a first reference point for the influence that might be indirectly exerted by the group of the corresponding members on the structure of full members. It shows the age distribution at the time of election of corresponding and full members elected between 1980 and 2005. Both the age distribution of full members and that of corresponding members exhibit an approximately symmetric distribution for both sections. Since the predominant part of the full members is elected from the pool of corresponding members, the average age of corresponding members is about 51 years compared to 57 years for full members. The standard deviation amounts in both cases to approximately 6 years.

As previously mentioned the transition from corresponding to full member represents a key factor since the latter group of members is selected predominantly from among the former group and thus the age of corresponding members implicitly presents a control to influence the age of full members. Hence, the target to lower the age of full members could be obtained by targeting a lower age at entry for corresponding members.

An alternative possibility to obtain a similar effect exists by way of a shortened "waiting period", which is represented in Figure 9. The average waiting period of corresponding members to become full members is characterised by a rather fluctuating pattern and was about 9 years in 1976-80, i.e., a corresponding member elected in the period 1976-80 was elected full member after approximately 9 years. 
Figure 8: Age distribution of corresponding ( $\mathrm{cm})$ and full members (fm) elected between 1980 and 2005 by section.

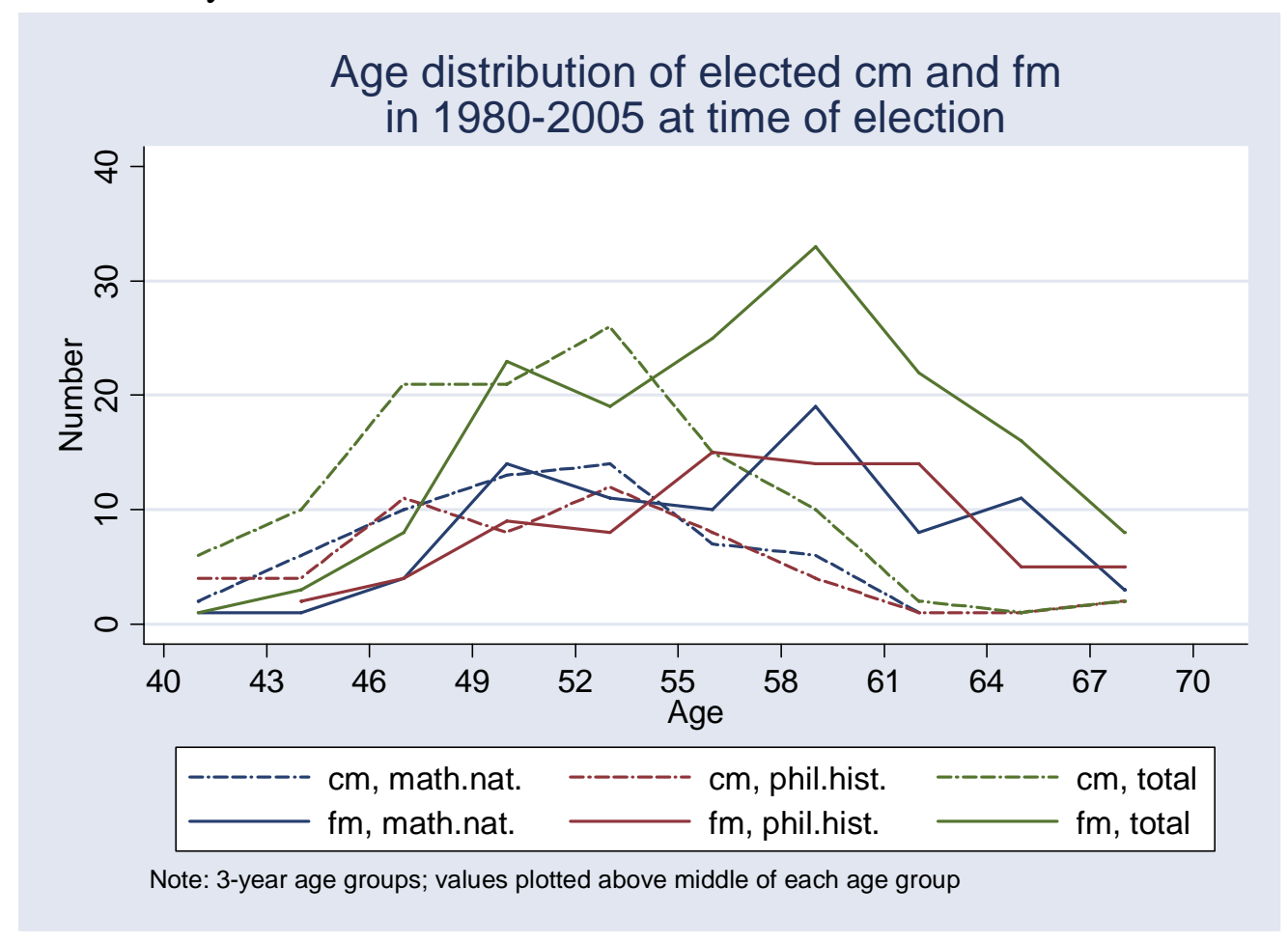

In accordance with Figure 10 the proportion of corresponding members ever to become full members presents itself strongly varying over time as well. 59\% (math.nat. section) and 57\% (phil.hist. section) among the corresponding members elected in 1976-80 later became full members. While the maximum value in the past was about $86 \%$ (186670, math.nat. section), the lowest about 25\% (1886-90, in the same section). Due to rightcensoring, the proportion of corresponding members ever to become full members drops strongly towards the end of the measurement period (the same argument holds for Figure 9 as well). 
Figure 9: Average number of years that corresponding members "waited" until they were elected full members, by section (for 5-year cohorts)

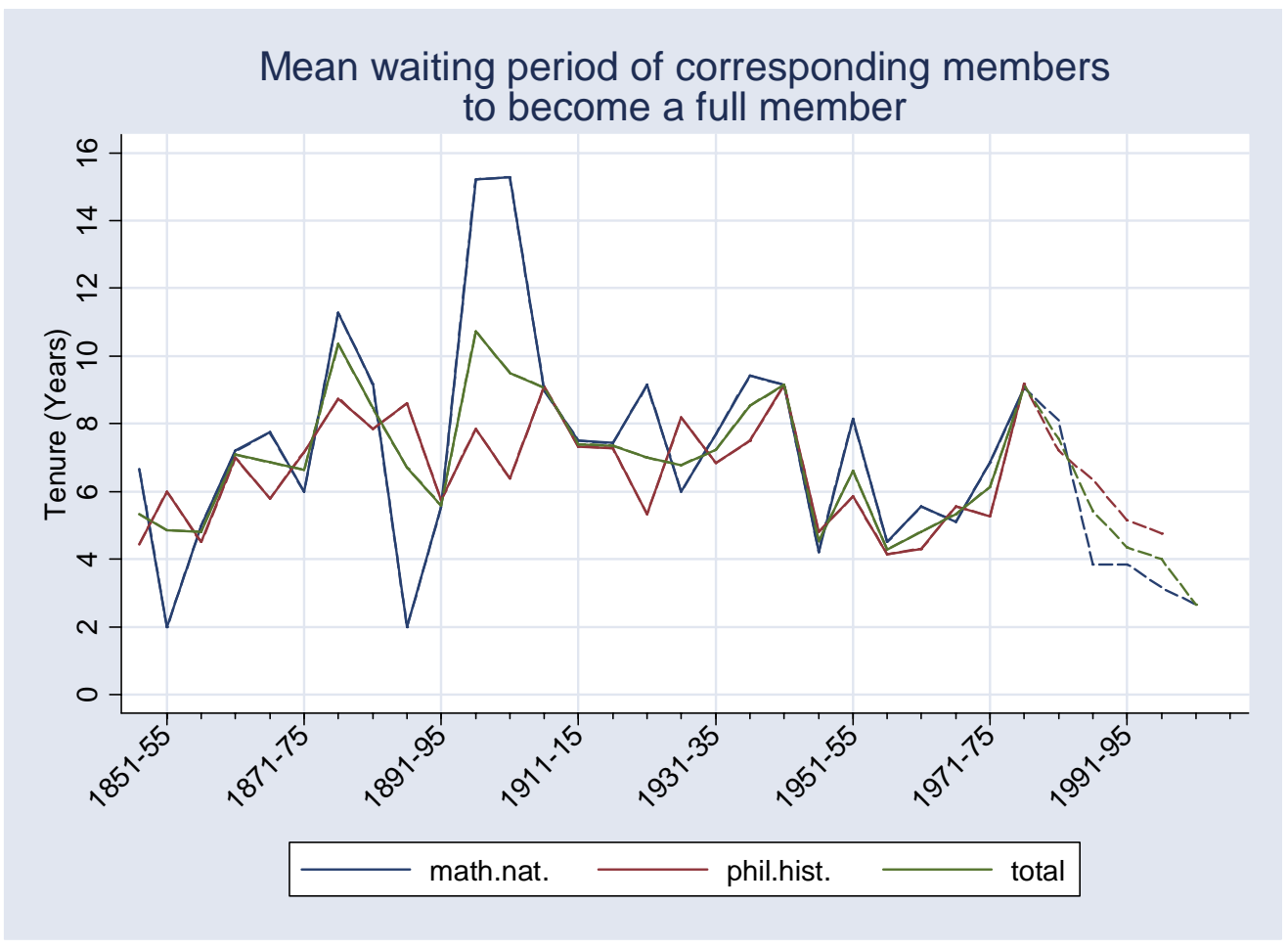

Figure 10: Share of corresponding members ever to become full members, by section (5year cohorts)

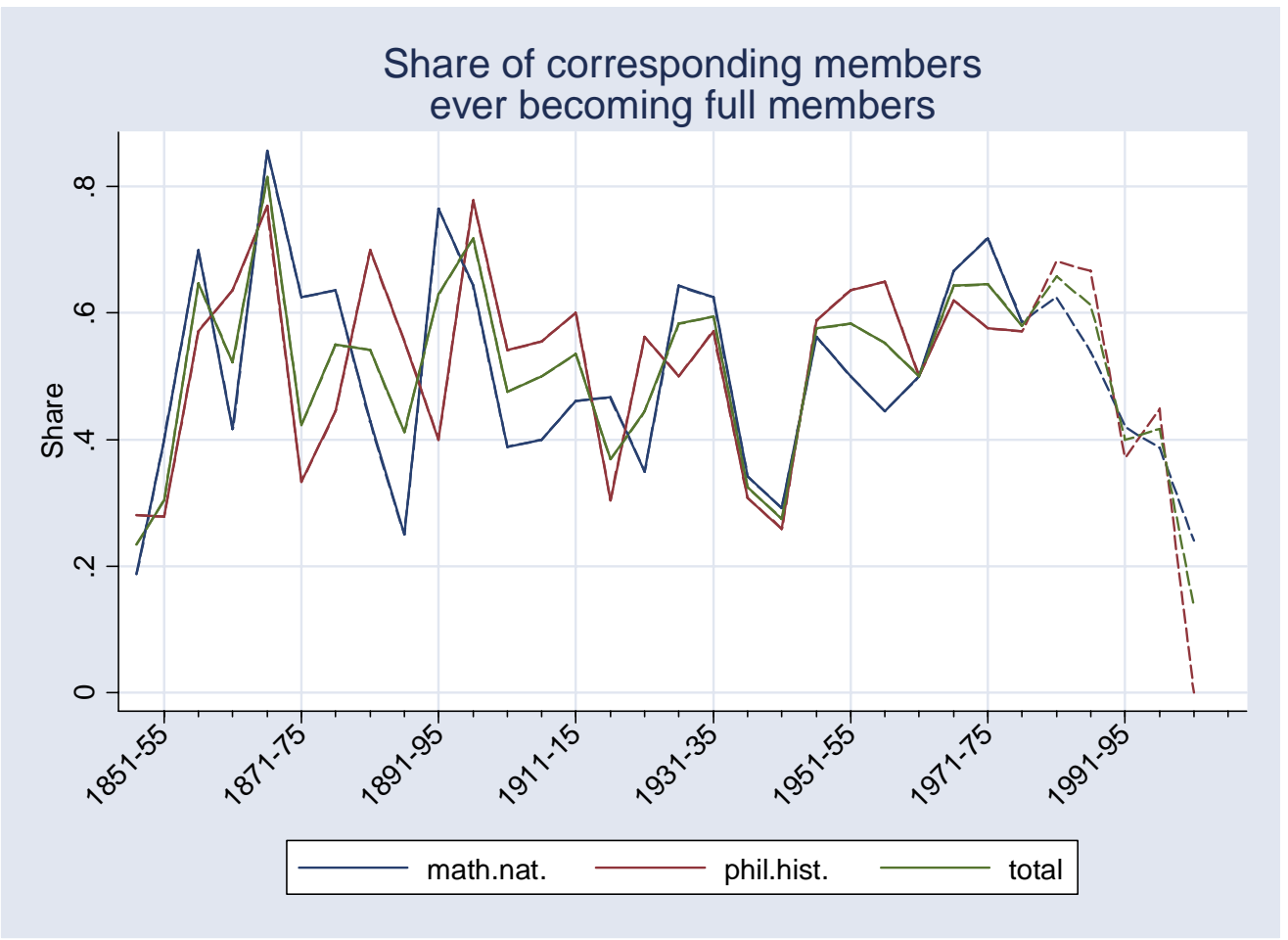




\subsection{The Low Mortality of Academy Members}

In accordance with general population ageing, Figure 11 confirms that the average age at death-which determines the end of membership in the Academy-rose continuously within our subpopulation. In 1851-55 a full Academy member died at the average age of 63 years, while the age at death was 74 years in 1931-35 and 82 years in 1996-2000. As a consequence the increasing mean age at death contributed to the rising average time spent as a full member.

Below we compare the mortality of the special subpopulation of the members of the Academy to that of the Austrian population as a whole. Our aim is to get a feeling for whether Academy members are subject to a comparatively high, low or average mortality.

We compare the mortality of Academy members with the average male mortality in Austria, which was obtained from life tables published by Statistics Austria and the Max Planck Institute for Demographic Research. Due to the low number of female members we conduct the mortality comparison only for the male members. Since we did not find any statistically significant differences between the survival functions of full and corresponding members, the following analyses is conducted for full and corresponding members together

Figure 11: Mean age at death per section (5-year periods) for full members

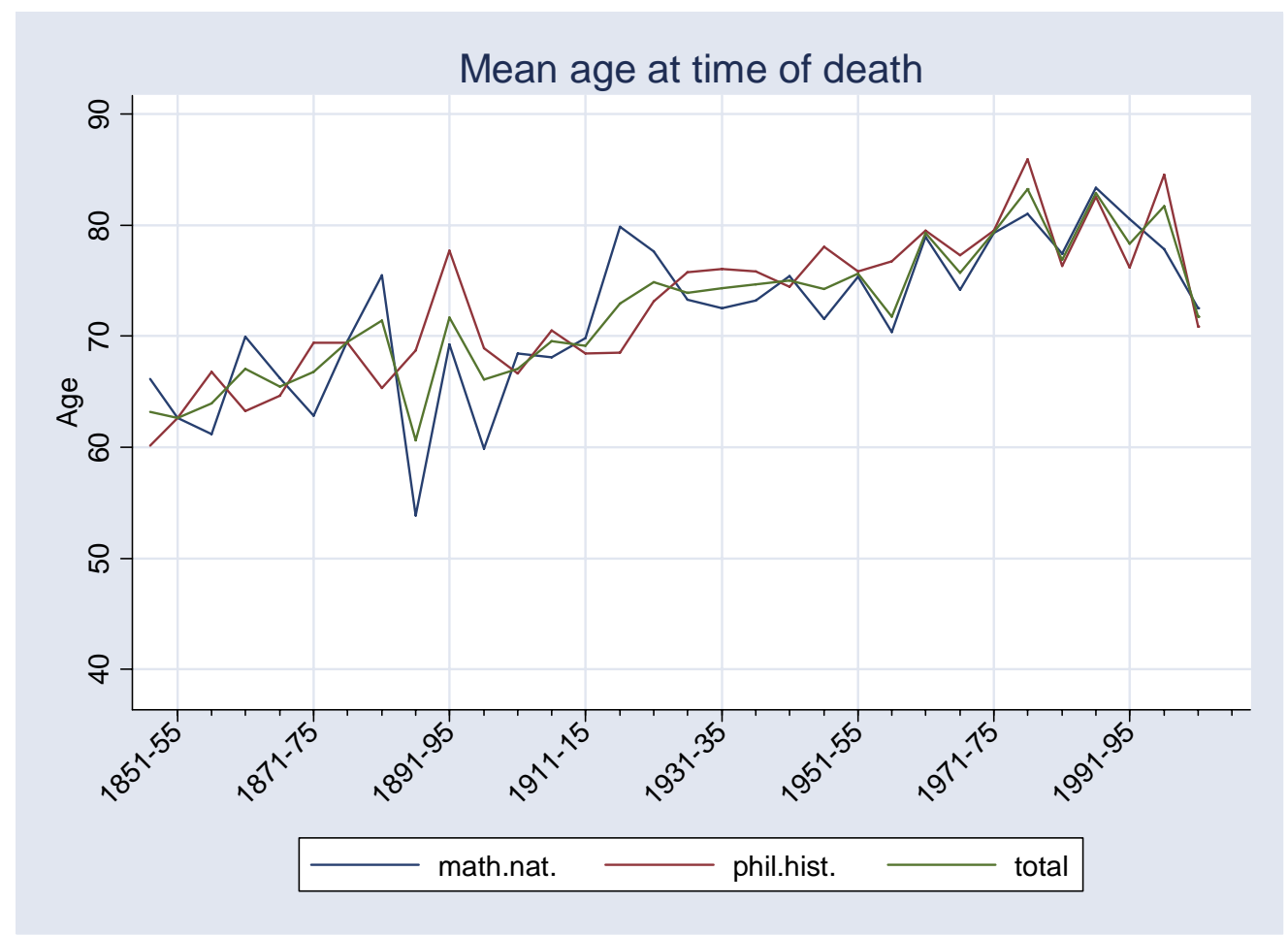

Using the mortality rates from the life tables (Max Planck Institute for Demographic Research 2005; Statistics Austria 2005) an expected number of deaths is derived. The 
relationship of the actually observed deaths to this expected number of deaths determines the standardised mortality ratio, SMR.

Table 2 shows the comparison of the number of deaths of the corresponding and full members in the period 1986-1995 with the mortality rates of the Austrian male population of 1991/92. In comparison with the total population the SMR is below 1 for all age groups. This implies that the male Academy members register fewer deaths than if they were subject to the average male mortality in Austria. As evident in Table 2, the extent of the mortality difference varies with age: the older the members of the Academy, the larger the SMR, i.e., the difference in the number of deaths shrinks. In the literature over differential mortality, this decrease in mortality differences with age is attributed among other things to a selection effect (Marmot and Shipley 1996; Crimmins 2005).

In summary, from 1986 to 1995, the members of the Austrian Academy of Sciences aged between 50 and 90 years registered only about half of the deaths that the Austrian life table for the total population from 1991/92 would have implied. For the period 1996-2005, there is a similar mortality difference in the comparison to the life table 2001/02.

Table 2: Comparison of the mortality of corresponding and full members in the time period 1986-1995 with the life table of the Austrian male population (and of that with tertiary education) of 1991/92.

\begin{tabular}{l|c|cc|cc}
\hline & & \multicolumn{2}{|c|}{ Total population } & \multicolumn{2}{c}{ With tertiary education } \\
Age & Observed deaths & Expected deaths & SMR & Expected deaths & SMR \\
\hline $50-70$ & 11 & 24.4 & $0.45^{* *}$ & 13.0 & 0.85 \\
$70-90$ & 42 & 72.5 & $0.58^{* *}$ & 58.8 & $0.71^{*}$ \\
\hline total & 53 & 96.9 & $0.55^{* *}$ & 71.8 & $0.74^{*}$ \\
\hline
\end{tabular}

Legend: $* * \mathrm{p}<0.01,{ }^{*} \mathrm{p}<0.05$

The above result is not surprising. Decreasing mortality with rising education and higher socio-economic status is well documented and generally valid world-wide. These differences could be determined in each country for which appropriate data are present (Kunst and Mackenbach 1994; for Austria, see Doblhammer-Reiter 1996, Doblhammer et al. 2005 and Schwarz 2005). Below we examine whether mortality differences still persist between the members of the Academy and the Austrian population with tertiary education, or whether the mortality difference of the Academy members to the total population is solely due to the higher education level. We use mortality rates of Austrian men with tertiary education (Doblhammer et al. 2005) as reference rates for the computation of the standardised mortality index. As evident in Table 2, the SMR-although higher than before-is still below 1! Over all age groups considered, the corresponding and full members registered about 2\% fewer deaths in the years 1986-1995 than would have been the case under the age-specific mortality rates of Austrian men with tertiary education in 1991/92. 
Figure 12: Life expectancy at age 60 of Academy members compared to Austrian life table estimates.

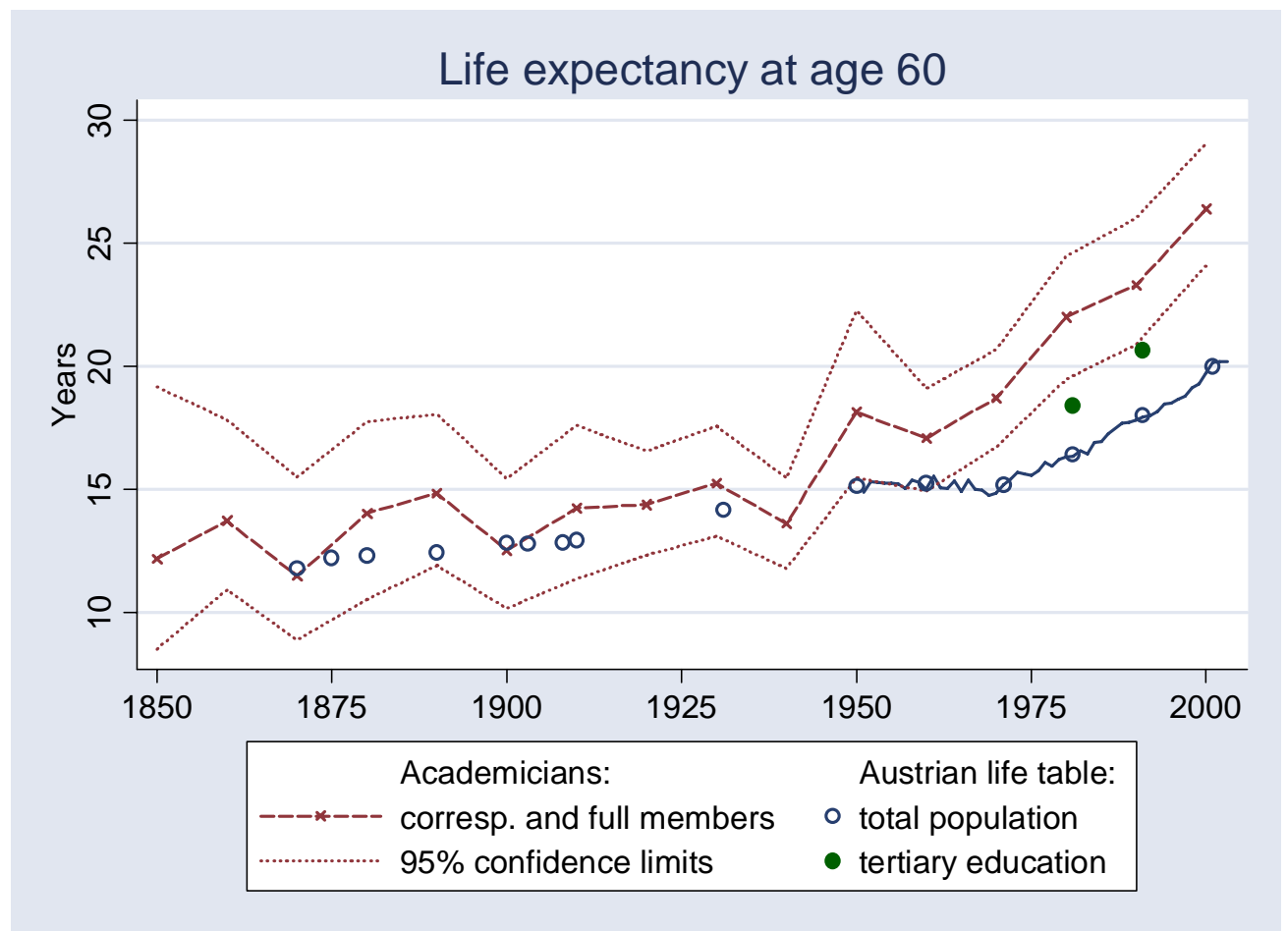

Figure 12 compares the life expectancy of Academy members at the age of 60 with the corresponding figures of the total population. With some exceptions the life expectancy of the Academy members at age 60 is slightly above the corresponding value for the Austrian male population. Starting from the mid-20th century, the life expectancy of Academy members rose more steeply as compared to that of the Austrian population as a whole. Around the turn of the century the difference in the further life expectancy at the age of 60 amounted already to approximately 6.5 years. For the population with tertiary education, the life expectancy at the age of 60 - expectedly_lies between the estimates for the Academy members and for the Austrian male population.

An increase of the social differences in the number of deaths was confirmed also in other studies (e.g., Marmot and McDowall 1986; Pamuk 1985). In particular Pamuk (1985) finds that the social gradient of the mortality rose in England and Wales for the 1950s which agrees with our results. ${ }^{4}$

\footnotetext{
${ }^{4}$ A more detailed mortality analysis can be found in Winkler-Dworak (2006).
} 


\section{Age Structure of New Entrants and Projections of the Future Structure and Size of the Academy}

The future age distribution of Academy members will be influenced by three factors: the current age distribution of Academy members, the age distribution of new entrants and the mortality development.

To project the Academy population we postulate the same mortality development as in the latest forecast of death probabilities by Statistics Austria (Hanika and Klotz 2005), which were derived by employing the Lee-Carter method (Carter and Lee 1992; Lee 2000). The projected death probabilities were converted into death rates under the usual assumption of a uniform distribution of deaths over the age interval. For the age groups above 50, we assumed constant forces of mortality within the age interval instead.

As shown in the last section, the Academy members exhibit a mortality that is significantly lower than the Austrian general population. Therefore, we adjust the forecasted Austrian death rates according to the standardised mortality ratio for the most recent period $(S M R=0.5)$. Since the mortality differences decline for higher ages, we increase the adjustment factor for increasing age by $2.5 \%$ per year of age starting from age 80. This implies a SMR of about 0.74 at the age of 99 years.

Since the forecasted life table from Statistics Austria (Hanika and Klotz 2005) ends at the age of 99, we extrapolate the mortality for higher ages by assuming a logistic model (Perks 1932) based on the death rates between ages 80 to 99.

For the projection of the development of the age structure of the Austrian Academy of Sciences, we first project the number of members at the year $t$ surviving until $t+1$. The difference between the number of survivors below age 70 and the upper limit of 45 members per sections gives the number of vacant posts. The latter are filled according to the postulated age distribution of members at election, where we consider four alternative scenarios (see Figure 13):

Status quo: Average age distribution (approximated by a normal distribution) of new entrants observed during the last 25 years, i.e., 1980-2005.

Young: Only persons below age 55 are elected—distributed uniformly.

Old: Only persons aged 55 and above are elected—distributed uniformly.

Bimodal: Persons between age 40 to 49 and 60 to 69 are elected-distributed uniformly. 
Figure 13: Alternative projection scenarios of the age distribution of election

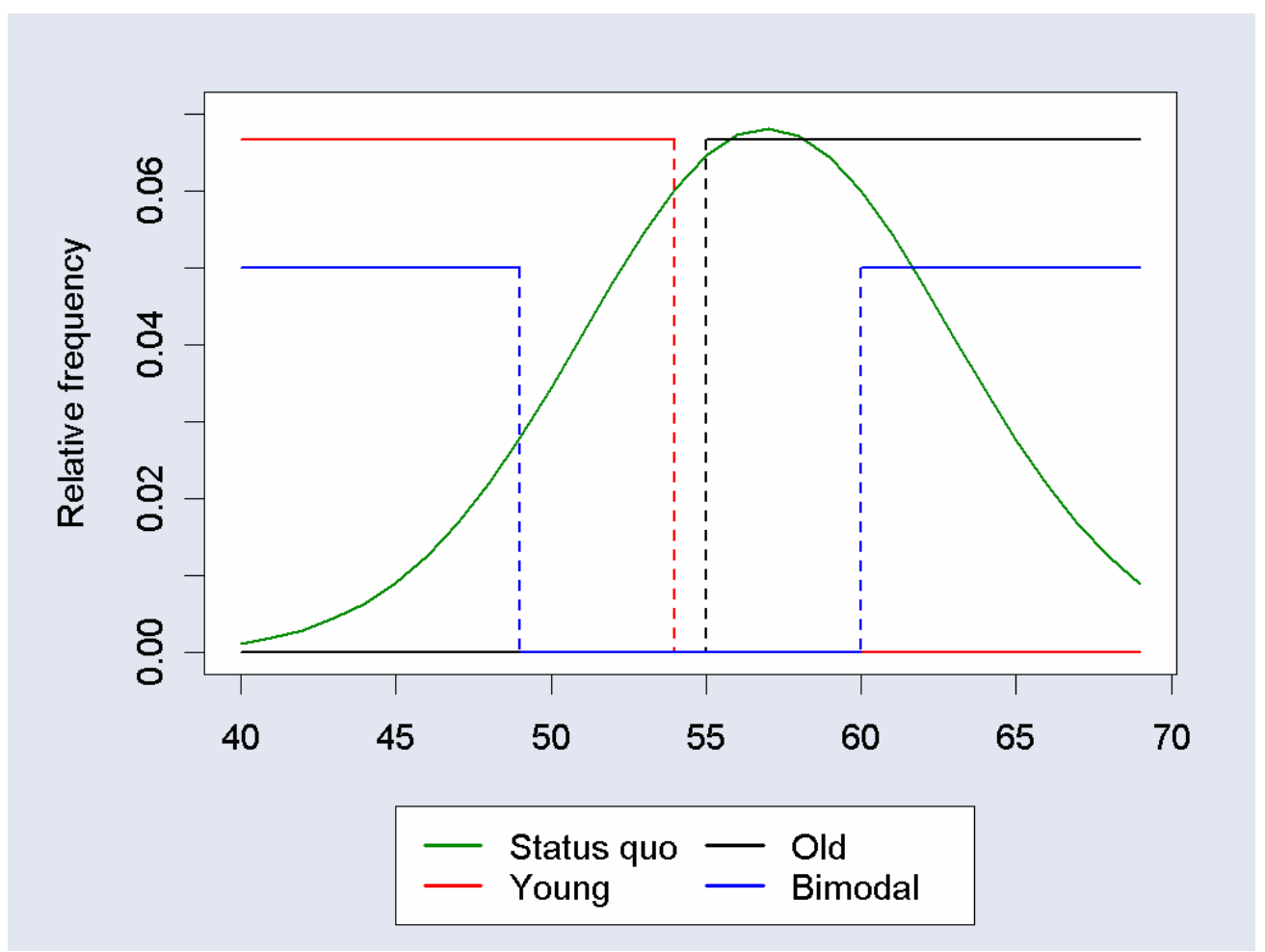

The average age of new entrants is about 57.2 years for the status quo scenario, 47.5 years for the young scenario, 62.5 years for the old scenario and 55 years for the bimodal scenario. The corresponding standard deviation is 6 years (status quo scenario), 4 years (young and old scenario) and 10 years (bimodal scenario).

The projection time horizon runs from 2005 up through 2050 and the initial population consists of 88 members in the math.nat. section and 79 members in the phil.hist section. Among these, 51\% (math.nat. section) and 57\% (phil.hist. section) are older than 70 years.

The projected number of vacancies over the period 2005-2050 is summarised in Figure 14 for the four scenarios of the age distribution of new entrants. The initial development is influenced by the actual age structure, i.e., by the number of members who exceed the age threshold of 70 (in the respective sections). It is after approximately 5 to 10 years that the influence of the observed age structure of 2005 weakens and the differences between the scenarios become visible. Only in the second half of the projection period, however, do the effects of the initial age structure entirely disappear. If the observed age distribution of new entrants over the last 25 years persists (scenario "status quo"), about 6 vacancies are expected per year by 2050. Assuming of the "young scenario", a phase would be reached around 2020 in which none or at most one new member could be elected! This period would last approximately a decade. Contrary to the status quo scenario a stabilisation of the number of vacancies under the young scenario would take a longer period and amount to about 3 vacancies. This can be explained by the smaller variance and the lower entrance age that implies a longer time interval until the members have surpassed 
the age threshold of 70 years and hence open up a vacancy. Under the old scenario in which only members of age 55 and above are elected the number of vacancies would be highest with 10 places per year. The bimodal scenario of newly elected members would result in a number of annual vacancies similar to the scenario of maintaining the current politics, i.e., the status quo scenario.

Figure 14: Projected number of vacancies (both sections together)

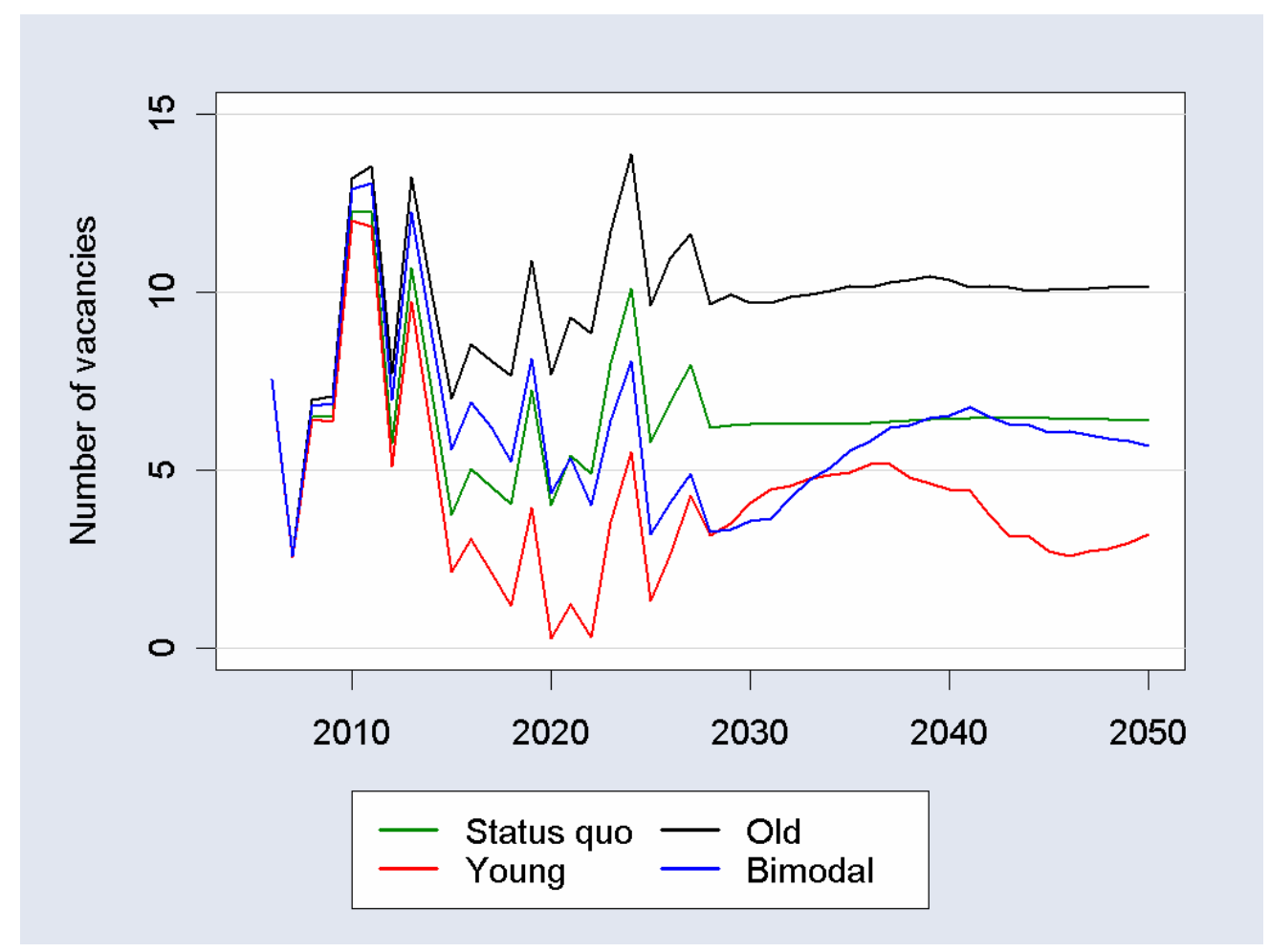

The strong differences in the annual number of vacancies under the different scenarios of the age distribution of new entrants cause accordingly different processes of the development of the total number of members over the time (Figure 15). With the highest number of vacancies per year, the old scenario would cause a rapid increase of the number of members from 167 in 2005 up to 290 members in 2050 corresponding to an increase of approximately 74 per cent. Under the status-quo and bimodal scenarios a more moderate increase of members up to 215 and respectively 200 members in 2050 would result. Under the young scenario an initial rise would be followed by a decrease in the number of members resulting in only 162 members in 2050. 
Figure 15: Projected number of members (both sections together)

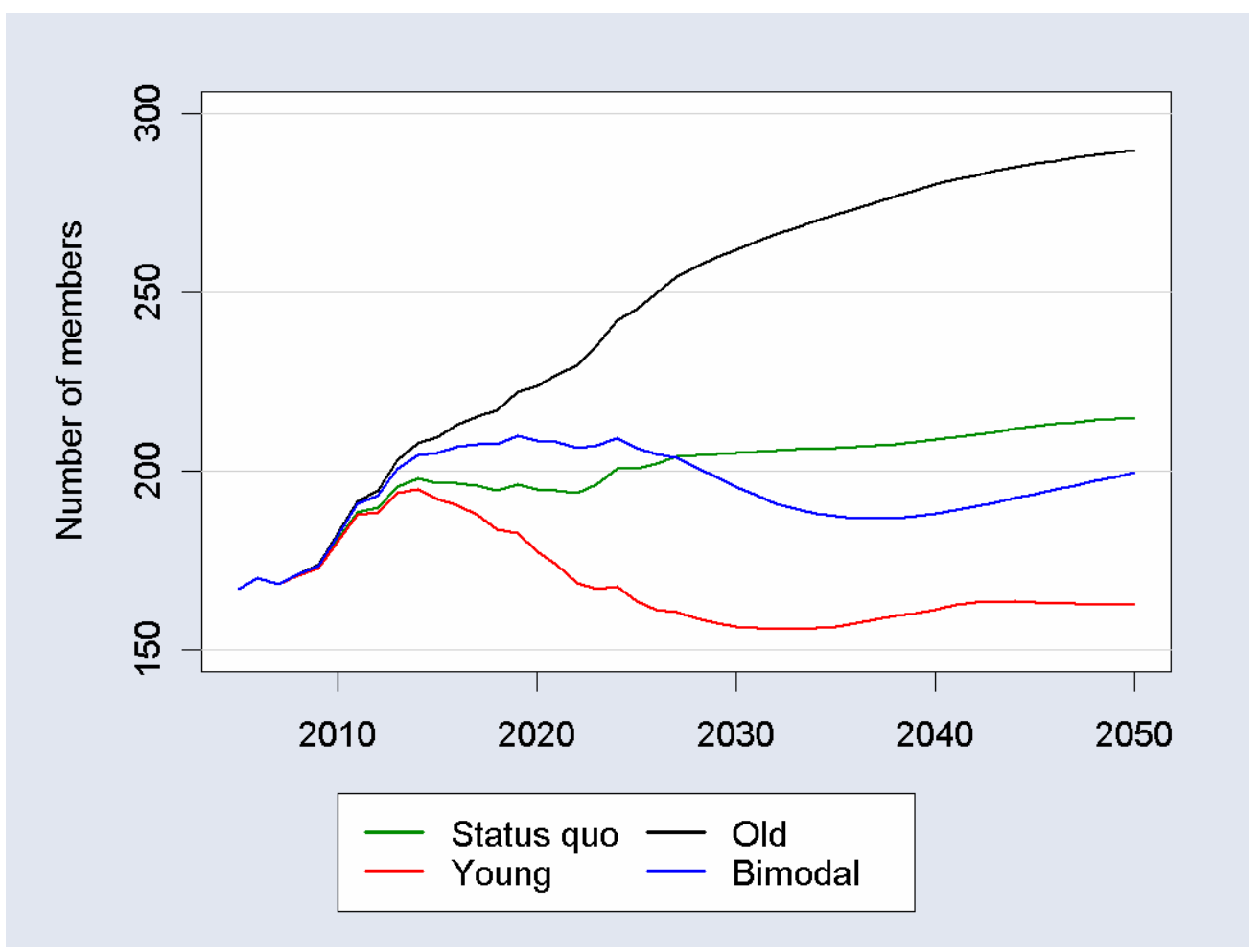

Figure 16 shows the development of the proportion of members below age 70 . Similar to the previous two figures, differences between the scenarios hardly exist in the initial projection time steps. Only after approximately 5-10 years the influence of the current age structure fades away. Maintaining the same age distribution of new entrants as in the last 25 years (status quo scenario), the proportion of members below age 70 would shrink to approximately $42 \%$ in 2050 . Under the young scenario the proportion of members below age 70 would even increase from 2015 to 2035 and finally approximate $55 \%$ by 2050 . Under the old scenario the proportion of members up to age 70 would shrink continuously down to $31 \%$ in 2050. Compared with the current proportion of members below age 70 (i.e., 54\%) this would correspond almost to a halving of this portion. The choice of the bimodal scenario would imply a share of $45 \%$ of members below age 70 up to 2050 .

The development of the members' mean age is represented in Figure 17. In contrast to the previous three figures, differences between the scenarios are visible from the beginning of the projection time period. As expected, the young (old) scenario implies the lowest (highest) mean age among the four scenarios presented. Clear differences in the mean age of the members between the status quo and bimodal scenario are visible, however. Under the status quo scenario the mean age would increase continuously, the development of the mean age under the bimodal scenario would be characterised by phases of shrinking mean ages. In the year 2050 the difference in the average age between the two scenarios would amount to approximately 3 years. ${ }^{5}$

\footnotetext{
${ }^{5}$ This difference would amount to 2 years if the mean age of the two scenarios were chosen to be the same.
} 
Figure 16: Projected proportion of members aged less or equal to 70 (both sections together)

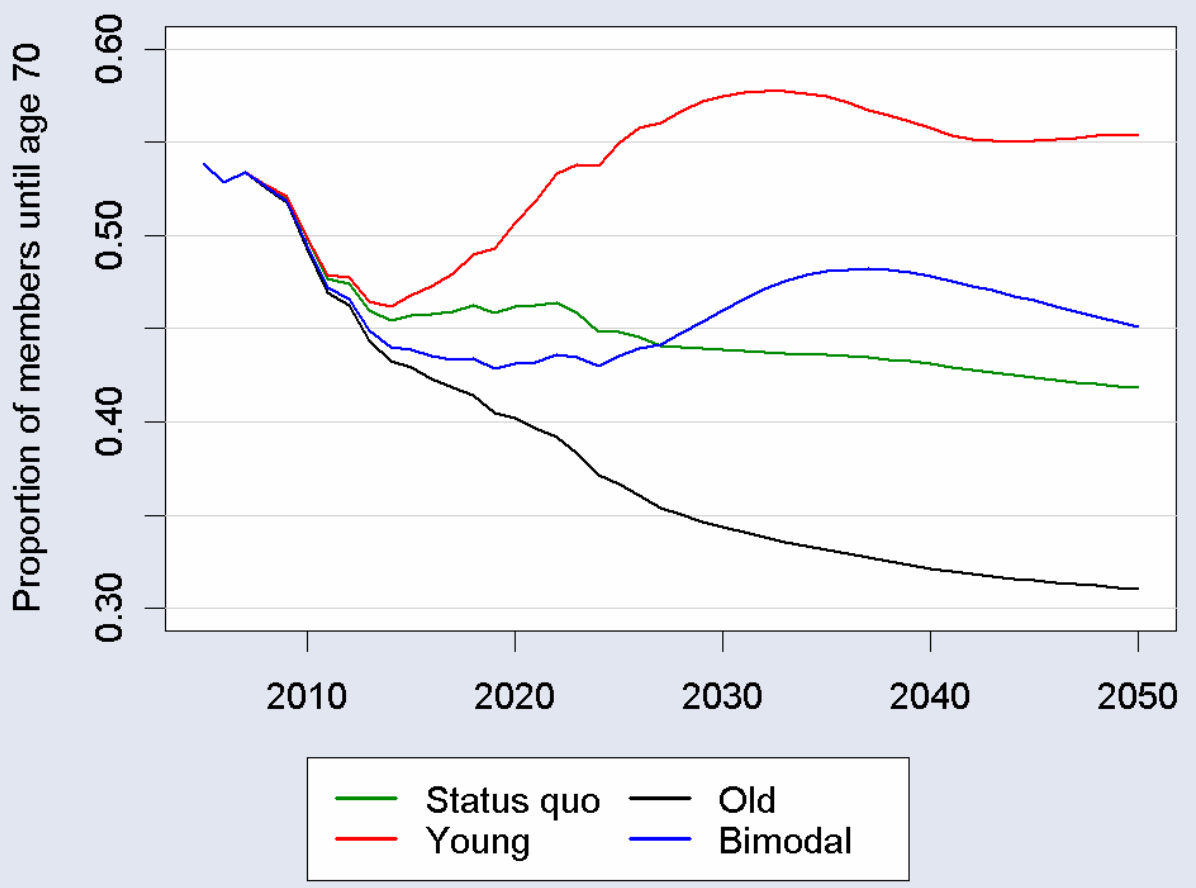

Figure 17: Projected mean age of members (both sections together)

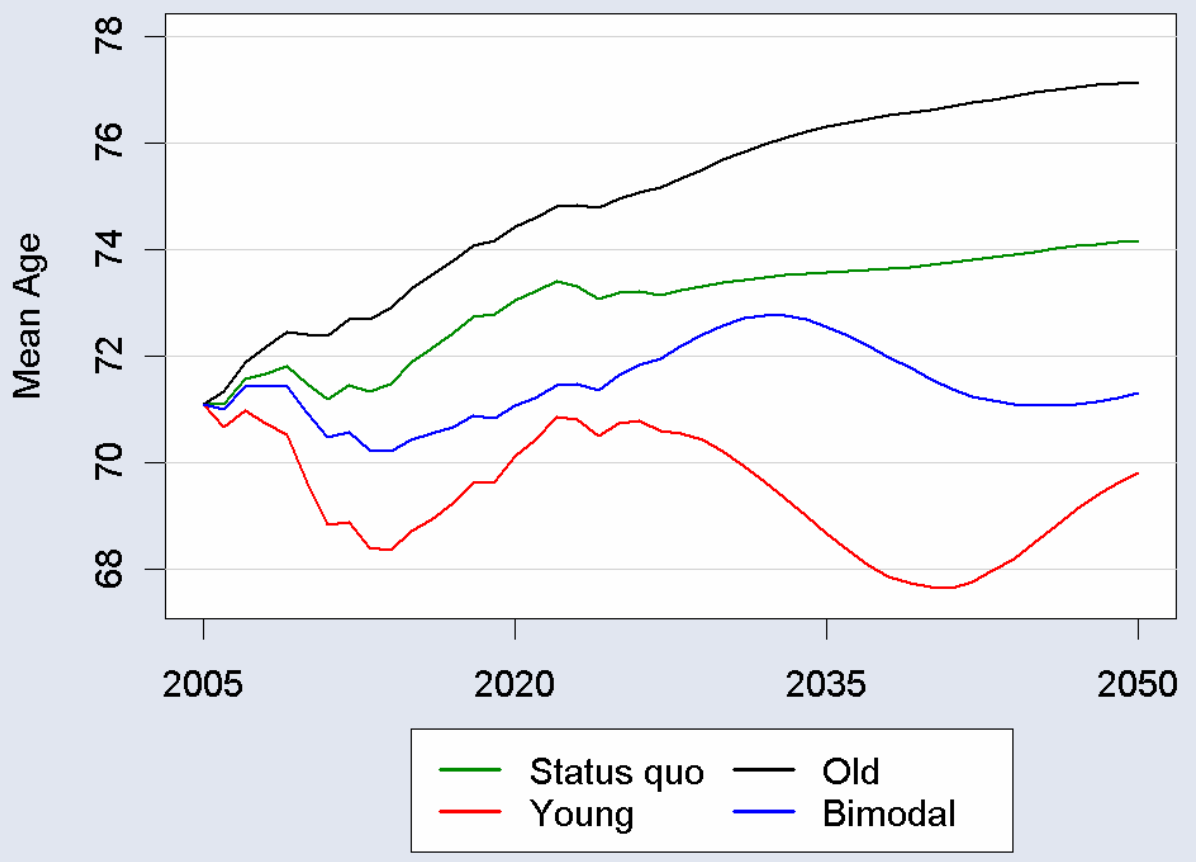


In summary, as Figures 14 through 17 indicate, the dilemma between a "young" society that only allows a small number of vacancies each year and a small number of the total stock of members vs. an "old" society that allows more vacancies and a larger stock of members each year becomes obvious. The bimodal distribution of the age at entry seems to be a compromise and, as we will show in the subsequent section, it also constitutes an optimal recruitment policy if the Academy's goal were to keep its member structure young and to allow a maximum number of recruitments each period.

\section{The Dilemma of a Stationary Academy}

\subsection{Few Young Versus Many Older Entrants}

Assuming that the Academy is interested in a young age structure and at the same time would like to appoint as many excellent scientists as possible without exceeding the maximum number of members below the age threshold of 70 years, then the Academy is confronted with the trade-off described in section 3. The connection between the annual number of vacancies and the mean age of Academy members is not new. The full member Gerhart Bruckmann summed up this dilemma with an illustration:

With an average age at election of 55 years and ruling out mortality, a member has 15 remaining years until the age threshold. At a maximum number of 90 members, you are bound to see 6 vacancies per year on average. However, if entry at earlier ages were favoured (in order to establish a "younger Academy"), e.g., at 47.5 years, then these new members would stay in the system for 22.5 years until the statutory retirement age-resulting in 90/22.5 = 4 vacancies per year.

This means that the younger the age at election, the longer the tenure in the Academy and thus the lower the rate of rejuvenation. These simple calculations are based on the fundamental identity of a stationary population where the stock equals the number of births multiplied by the life expectancy and in our case:

$$
M=R T
$$

where $M$ denotes the total size of the Academy, $R$ the annual intake and $T$ the mean length of tenure. In the Austrian case we have $M=90,0 \leq T \leq 30$ (assuming a minimal age at entry of 40 years and an upper age limit of 70 years).

The optimal election policy depends on the weights which are assigned to the conflicting goals, i.e., electing as many new members or favouring a young age structure which implies a long duration of membership. Let us denote the weights of the former by $\alpha$ and those of the latter by $\beta$, where the coefficients sum up to one, i.e., $\alpha+\beta=1$. Then the objective of the Academy is given by

$$
\operatorname{Max}(V=\alpha R+\beta T)
$$

The above decision problem is graphically illustrated in Figure 18. Equation (1) represents all feasible combinations of the number of newly elected members $R$ and the duration spent as a member $T$, given a constant population. This trade-off corresponds to a hyperbola in Figure 18. The objective function in (2) results in a straight line with a negative slope. The aim is to find a point on the hyperbola at which the straight line results 
in the highest value $V$. One finds this point by parallel translation of the straight lines to the right.

For the analysis we assumed two additional restrictions: $R \leq 90$ and $T \leq 30$. The first condition implies that not more than 90 members can be elected at any time point. The second condition implies a limit on the duration of members of 30 years that together with the age limit of 70 years implies a minimal age of 40 years at election.

If the objective of a young Academy is the main aim, i.e., $\beta$ is sufficiently larger than $\alpha$, the slope of the line (2) is relatively flat. In this case the point $A$ yields the maximum of the objective function given the addition restriction on $R$ and $T$ as indicated above. In point $A$ young entrants with a long duration in the Academy are optimal. In the opposite case, i.e., $\alpha$ is sufficiently larger than $\beta$, and hence more weight is put on the number of vacancies, point $B$ is optimal where many old members with a short duration are elected.

Figure 18: Trade-off between new entrants $R$ and duration $T$

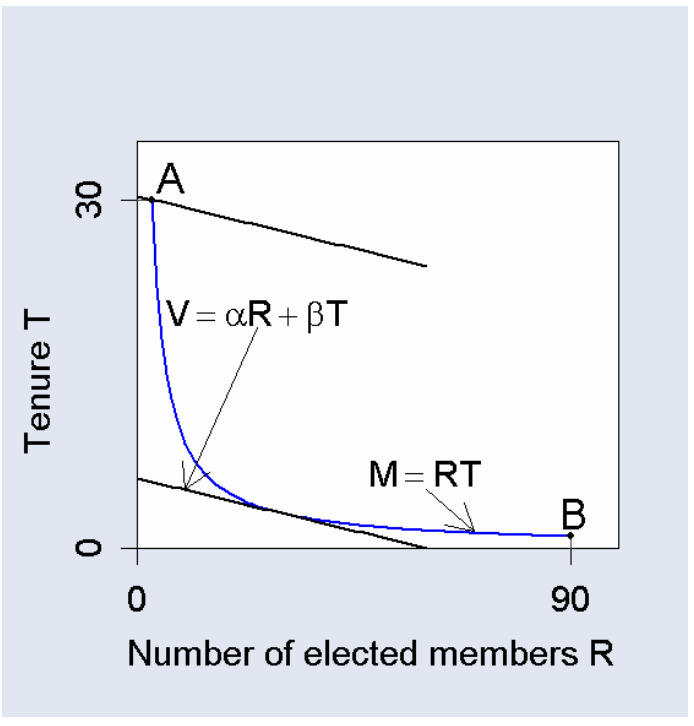

(a) $\alpha<\beta$

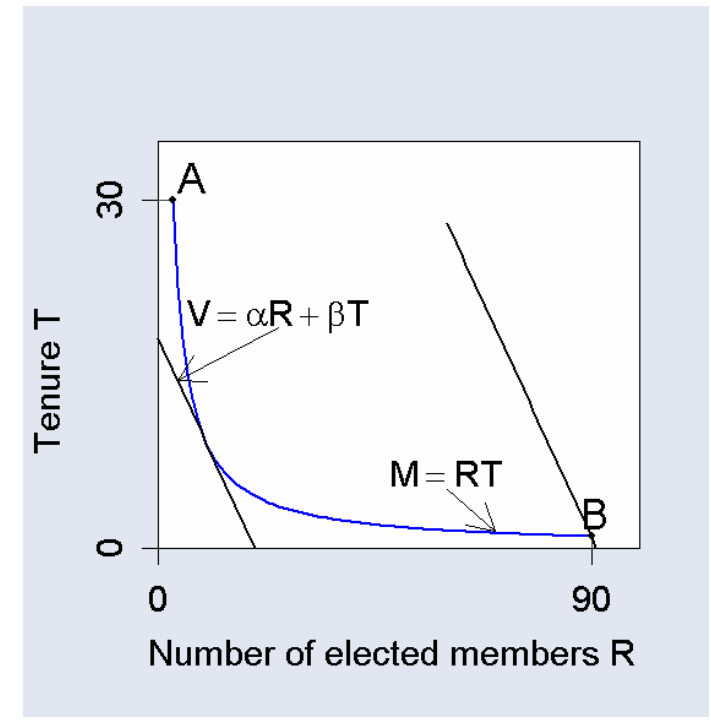

(b) $\alpha>\beta$

\subsection{The Optimal Generation Mix}

Applying optimal control theory, the optimal trade-off between new entrants and the mean age of the members can be described adequately. Since age and tenure of members in the Academy, respectively, play a key role in the objective of our set-up, a distributed parameter control problem can be formulated. The well-known McKendrick partial differential equation (Keyfitz and Keyfitz 1997) formalises the development of Academy members over time and age. The age distribution of the new entrants constitutes the control variable while the number of members constitutes the state variable. Equation (2) above gives the objective function. 
A variant of Pontrjagin's maximum principle (Feichtinger et al. 2003) can be applied to derive the optimal age distribution of entrants. Below we only demonstrate the results for the stationary case (the transient case has been shown in Section 3). We also abstract from mortality before the age limit of 70 years. A detailed model description can be found in Feichtinger and Veliov (2006). ${ }^{6}$

A robust result (with respect to parameter settings) is the U-shape of the shadow price of a full member as a function of age (Figure 19). The shadow price measures the marginal increase in the value of an additional member along the optimal trajectory. It is sensitive to the weights $\alpha$ and $\beta$. The larger $\beta$, i.e., the more dominant the objective of a young Academy, the larger the shadow price of young versus old entrants. The optimal shadow price determines the optimal age structure of members (Figure 20). Most importantly, the U-shape of the shadow price implies an optimal mix of young and old entrants. Such a policy is ubiquitous in other areas (sports, labour economics, etc.) as argued in personal communication by Warren Sanderson "Awarding young members means awarding scientific excellence, awarding old members means awarding life long achievement”.

\footnotetext{
${ }^{6}$ The following figures were developed by Vladimir Veliov and are included with his approval.
} 
Figure 19: Shadow price of a full member by age in the stationary case neglecting mortality below age 70 ( $\theta$ and $70-\tau$ define the age limits of the 'optimal election policy'.)

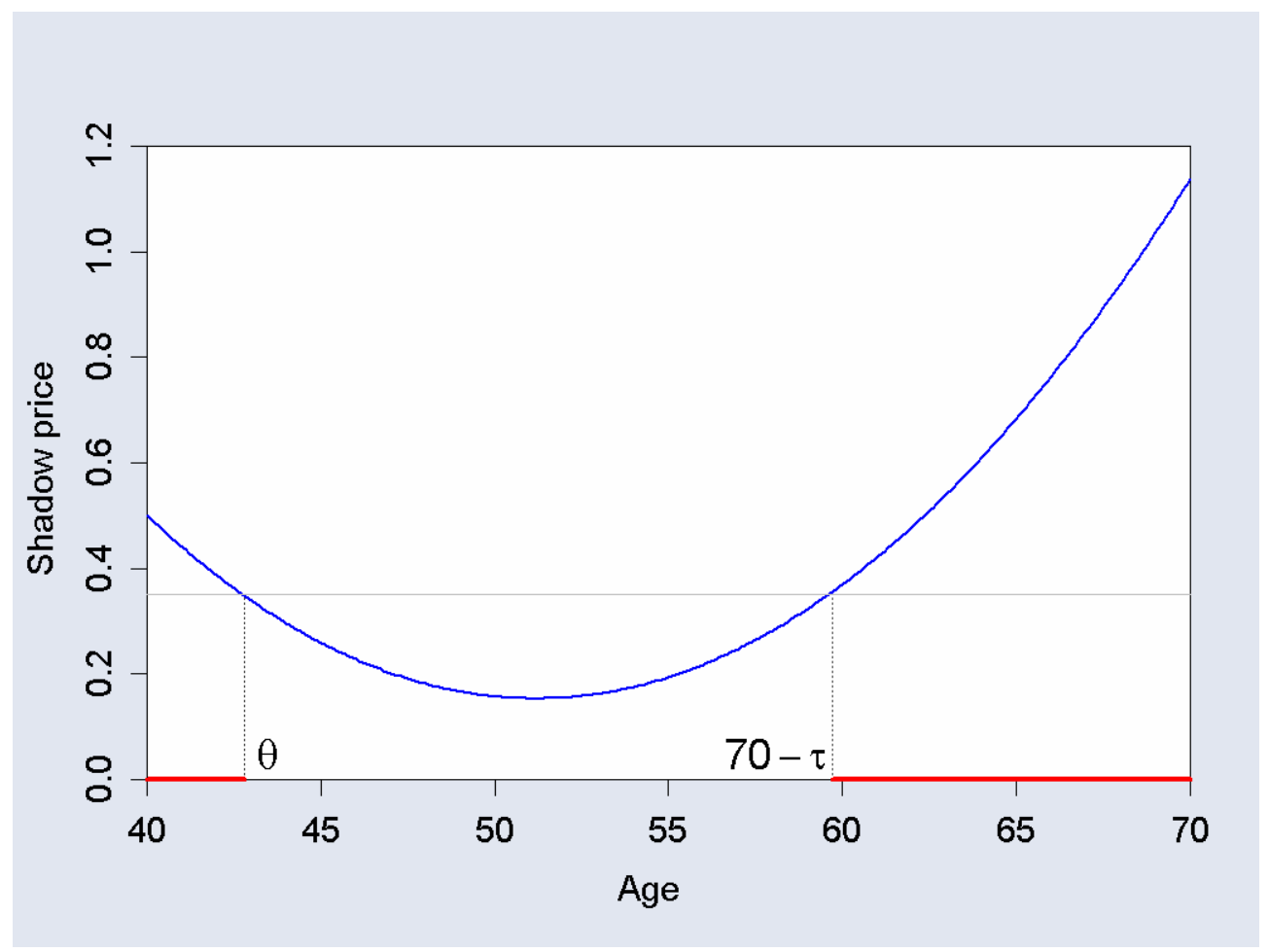

(a) $\alpha=\beta=0,5$

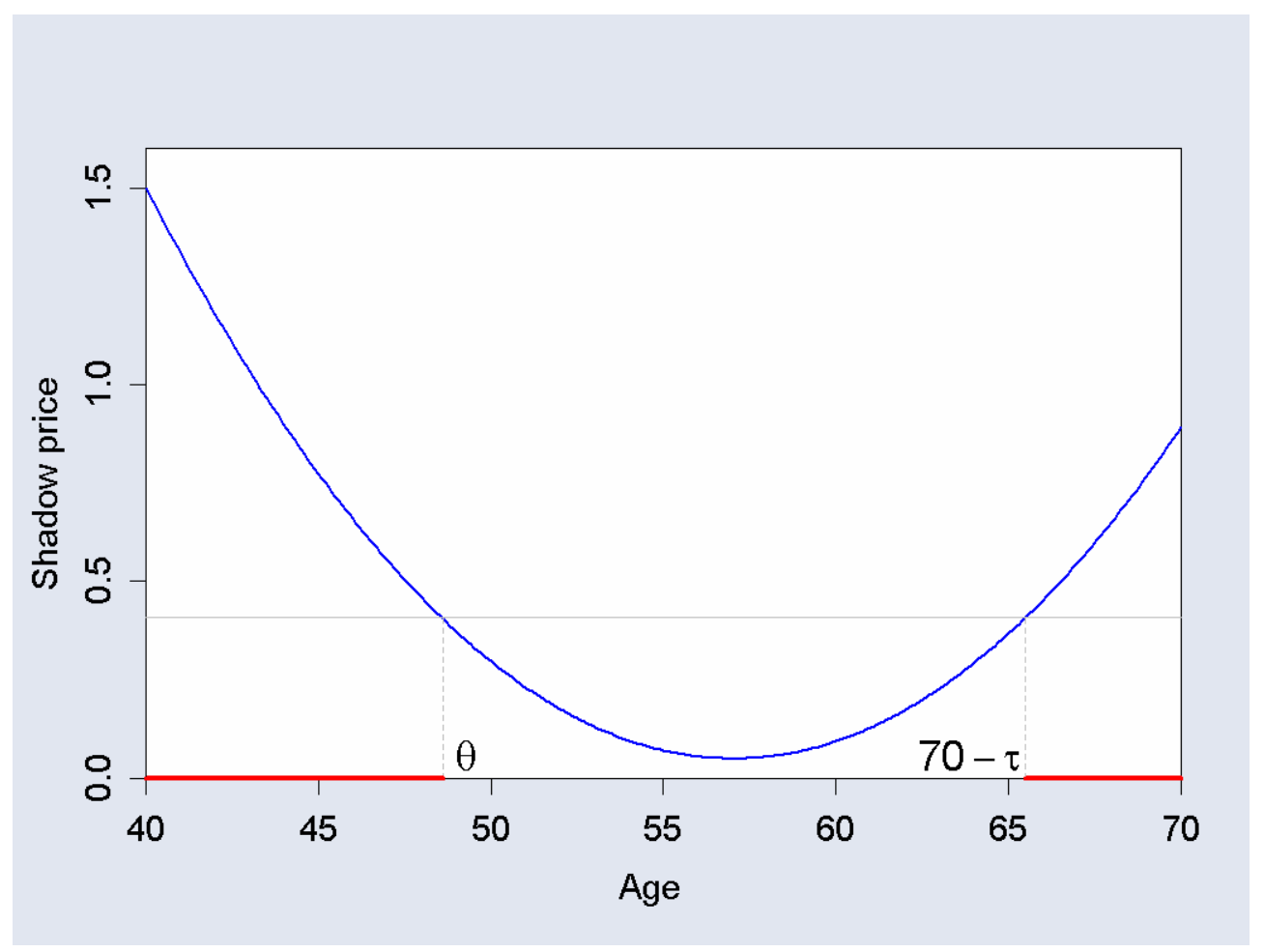

(b) $\alpha=0,1, \quad \beta=0,9$ 
Figure 20: Optimal age structure of full members in the stationary case neglecting mortality below age 70 ( $\theta$ and $70-\tau$ define the age limits of the 'optimal election policy'.)

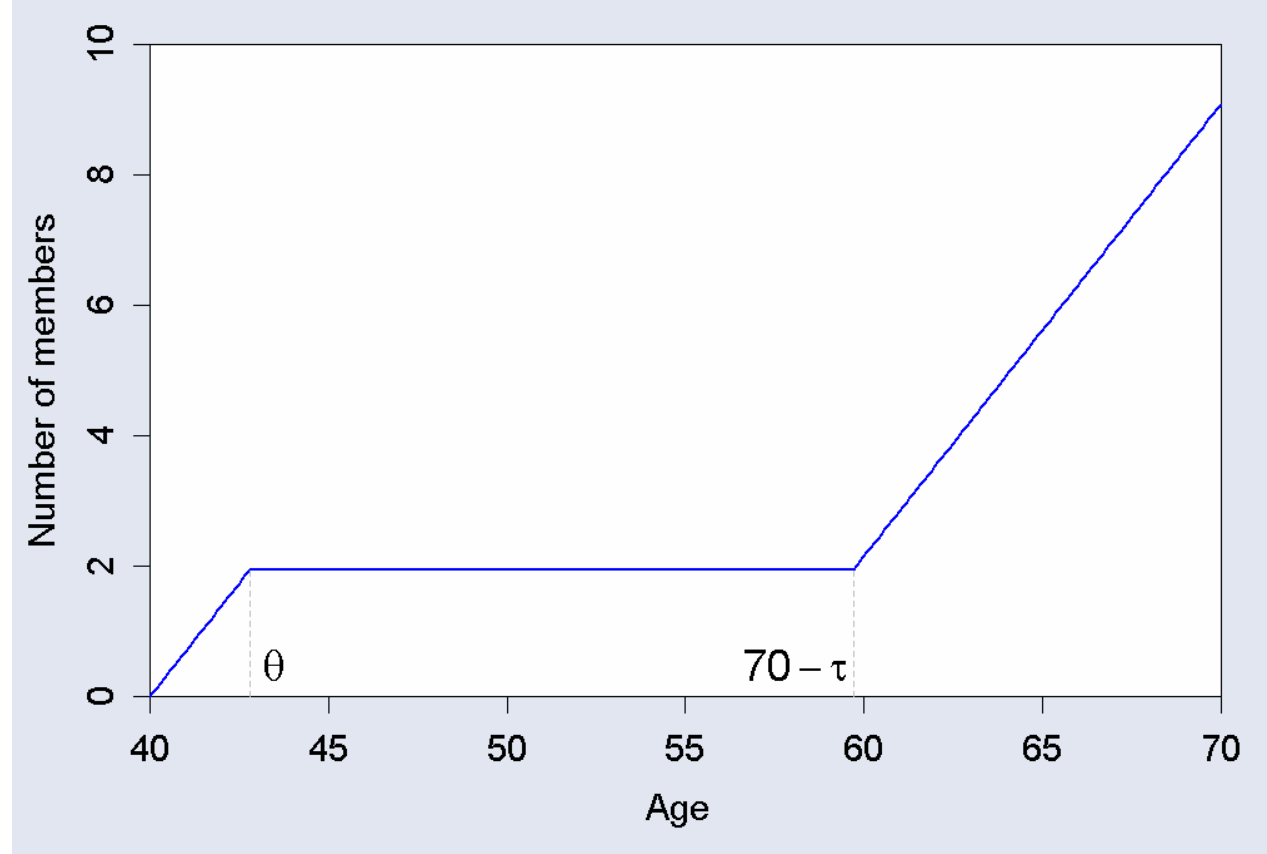

(a) $\alpha=\beta=0,5$

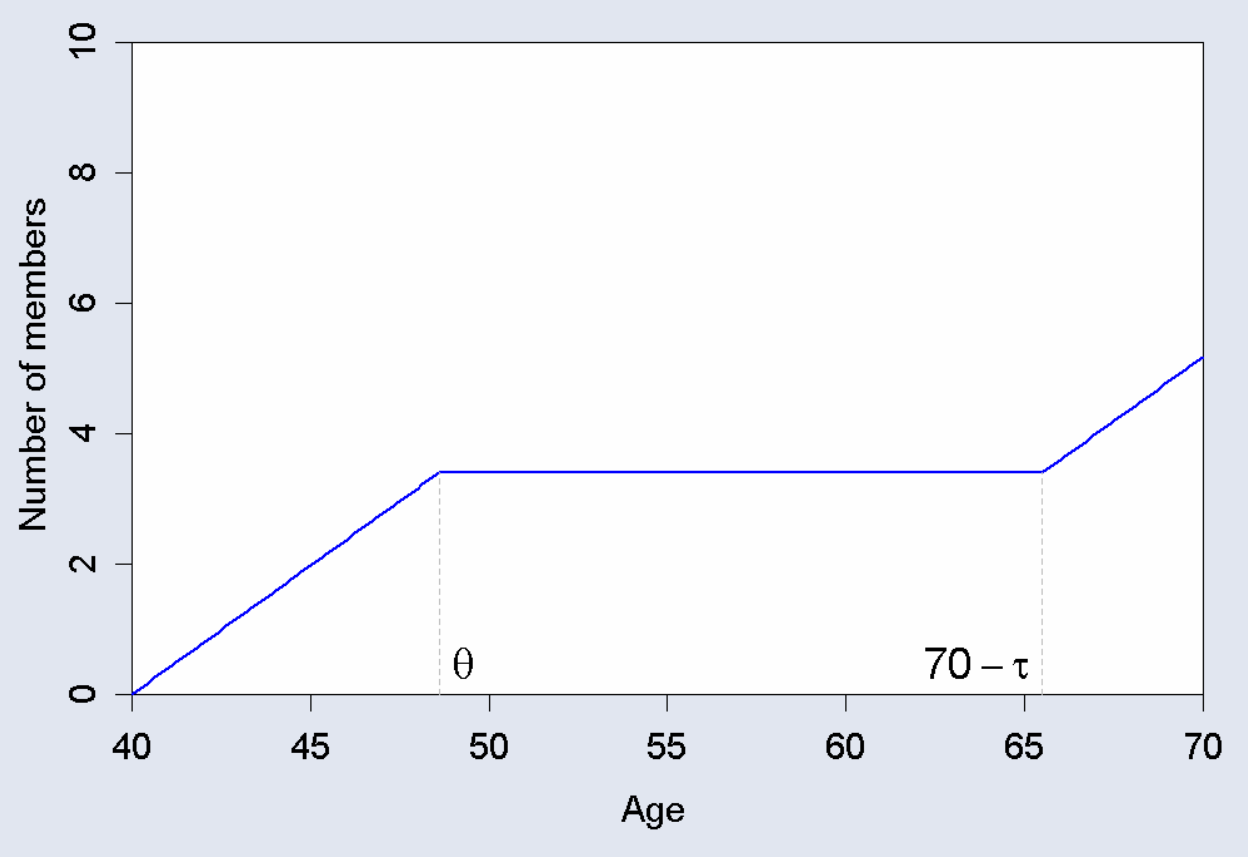

(b) $\alpha=0,1, \quad \beta=0,9$ 


\section{Conclusions}

In this paper we aimed to discuss - on the basis of a short historical sketch-certain planning problems of the Academy, which arise among other things in connection with the rising life expectancy of its members. Our aim was to illustrate to what extent methods of demography and population dynamics can contribute to obtain a more detailed insight into the structural problems of learned societies.

Under the premise that the Academy is interested in keeping a young age structure of its members and on the other hand to elect as many new members per year as possible, the statutory maximum number of 45 full members per section implies a conflict between those two objectives. Applying demographic projection methods, we illustrated the effect of the age distribution of new entrants on the number of vacancies each year and on the age structure of the members, thus illustrating the above mentioned trade-off. A bimodal age distribution of new entrants turned out to be optimal with respect to the above mentioned objective. By applying optimal control theory we sketched that such a policy is indeed an optimal solution under the above objectives.

Our study is not only relevant for learned societies but also for other subpopulations, whose dynamics (i.e., temporal development and structuring) can be studied with demographic methods illustrated in this paper. These examples include universities, armies and companies for instance. Formally related are migration dynamics where in- and outmigration can occur at any age. For instance, related research questions are: How many migrants at what ages would have to immigrate in order to achieve a given goal-for instance zero growth-in the receiving country? Can the birth development be counteracted by immigration at all? (Arthur and Espenshade 1988; Feichtinger and Steinmann 1992; Mitra 1983; Schmertmann 1992) In personnel management studies there are related research questions: How do the career prospects for members of an organisation decrease if after a growth phase the system stagnates or even shrinks? While this question arises for example within the range of our universities concerning the opportunities for advancement from assistant to professor, it concerns likewise the problem of the transition from corresponding to full member (Feichtinger 1974, 1976; Feichtinger and Mehlman 1976; Henry 1971, 1972, 1975; Keyfitz 1973; Vaupel 1981).

In future work we intend to study in more detail the dynamics of corresponding members since they constitute the "pool" from which the predominant number of full members is elected. We also plan to conduct a comparative study among academies of other countries (Cohen 2003; Leridon 2004; Matthiessen 1999; Van de Kaa and de Roo 2006) where similar problems with the age dynamics exist. 


\section{References}

Arthur, W.B. und Espenshade T.J. 1988. Immigration policy and immigrants' ages. Population and Development Review 14. 315-326.

Carter, L. und Lee, R. 1992. Modeling and forecasting U.S. mortality: differentials in life expectancy by sex. International Journal of Forecasting 8 (3). 393-412.

Cohen, J.E. 2003. How many members will the National Academy of Sciences have? Unpublished manuscript (last revision: 2003-10-15).

Crimmins, E.M. 2005. Socioeconomic differentials in mortality and health at the older ages. Genus 61 (1). 163-176.

Doblhammer-Reiter, G. 1996. Soziale Ungleichheit vor dem Tod: Zum Ausmass sozioökonomischer Unterschiede in der Sterblichkeit in Österreich. Demographische Informationen 1995/96. Institut für De-mographie (ed). Österreichische Akademie der Wissenschaften. Wien.

Doblhammer, G., Rau, R. und Kytir, J. 2005. Trends in educational and occupational differentials in all-cause mortality in Austria between 1981/80 and 1991/92. Wiener Klinische Wochenschrift 117 (13-14). 468-479.

Feichtinger, G. 1974. Stochastische Modelle des Manpower Planning. Antrittsvorlesungen der Technischen Hochschule in Wien 42. Wien.

Feichtinger, G. 1976. On the generalization of stable age distributions to Gani-type manpower models. Advances in Applied Probability 8. 39-53.

Feichtinger, G. und Mehlmann, A. 1976. The recruitment trajectory corresponding to particular stock sequences in Markovian person-flow models. Mathematics of Operations Research 1.175-184.

Feichtinger, G. und Steinmann G. 1992. Immigration into a population with fertility below replacement level—-the case of Germany. Population Studies 46. 275-284.

Feichtinger G., Tragler, G. und Veliov, V.M. 2003. Optimality conditions for agestructured control systems. Journal of Mathematical Analysis and Applications 288. 47-68.

Feichtinger, G. und Veliov, V.M. 2006. On a distributed control problem arising in dynamic optimization of a fixed-size population. Forschungsbericht 300. Institut für Wirtschaftsmathematik, FG: ORDYS, TU Wien.

Hanika, A. und Klotz, J. 2005. Personal correspondence. 
Henry, L. 1971. Pyramides, statuts et carrières. I. Avancement à l'ancienneté. Sélection. Population 26 (3). 463-486.

Henry, L. 1972. Pyramides, statuts et carrières. II. Avancement au choix. Population 27 (45). 599-636.

Henry, L. 1975. Perspectives d'évolution d’un corps. Population 30 (2). 241-270.

Hittmair, O. und Hunger, H. 1997. Akademie der Wissenschaften. Entwicklung einer österreichischen Forschungsinstitution. Wien.

Jahn, B. 2001. Biographische Enzyklopädie deutschsprachiger Philosophen.

Keyfitz, N. 1973. Individual mobility in a stationary population. Population Studies 27 (2). 335-352.

Keyfitz, B.L. und Keyfitz, N. 1997. The McKendrick partial differential equation and its uses in epidemiology and population study. Mathl. Comput. Modelling 26 (6). 1-9.

Kunst, A.E. und Mackenbach, J.O. 1994. The size of mortality differences associated with educational level in nine industrialized countries. American Journal of Public Health 84 (6). 932-937.

Lee, R. 2000. The Lee-Carter method for forecasting mortality, with various extensions and applications. North American Acturial Journal 4 (1). 80-93.

Leridon, H. 2004. The demography of a learned society. The Académie des Sciences (Institut de France), 1666-2030. Population-E 59 (1). 81-114.

Marmot, M.G. und McDowall, M.E. 1986. Mortality decline and social inequalities. The Lancet. 274-276.

Marmot, M.G. und Shipley, M.J. 1996. Do socioeconomic differences in mortality persist after retirement? 25 year follow up of civil servants from the first Whitehall study. British Medical Journal 313. 1177-1180.

Matis, H. 1997. Zwischen Anpassung und Widerstand. Verlag der Österreichischen Akademie der Wissenschaften. Wien.

Matthiessen, P. 1998. Some demographic calculations relating to Danish members of the Royal Danish Academy of Sciences and Letters. In: Kuijsten, A., de Gans, H. and de Feijter, H. (eds). The joy of de-mography ... and other disciplines. Liber amicorum presented to Dirk van de Kaa on the occasion of his retirement as Professor at the University of Amsterdam. Thela Thesis. Amsterdam. 
Max Planck Institute for Demographic Research (ed). 2005. Human Life Table Database. [Online] MPIDR. Available from: URL: http://www.lifetable.de [accessed on 2005-0609].

Mitra, S. 1983. Generalization of the immigration and the stable population model. Demography 20. 111-115.

Pamuk, E.R. 1985. Social class inequality in mortality from 1921 to 1972 in England and Wales. Population Studies 39. 17-31.

Perks, W. 1932. On some experiments in the graduation of mortality statistics. Journal of the Institute of Actuaries 63. 12-57.

Sanderson, W. 2005. Personal communication.

Schlögl, K. 1992. Bericht des Generalsekretärs über die Akademiewahlen. Almanach 1992. Österreichische Akademie der Wissenschaften. Wien.

Schmertmann, C.P. 1992. Immigrants' Ages and the Structure of Stationary Populations with Below-Replacement Fertility. Demography 29 (3). 595-612.

Statistik Austria (ed). 2005. Statistisches Jahrbuch 2005. Statistik Austria (CD-ROM). Wien.

Schwarz, F. 2005. Widening educational inequalities in mortality: an analysis for Austria with international comparison. Working Paper 07/2005. Institut für Demographie. Österreichische Akademie der Wissenschaften. Wien.

van de Kaa, D.J. und de Roo, Yves. 2006. The members of the Royal Netherlands Academy of Arts and Sciences: 1808 to 2000. A demographic view. (Ms.)

Vaupel, J.W. 1981. Over-tenured universities: the mathematics of reduction. Management Science 27 (8). 904-913.

Winkler-Dworak, M. 2006. The low mortality of a learned society. Working Paper 05/2006. Institut für Demographie. Österreichische Akademie der Wissenschaften. Wien. 


\section{VIENNA INSTITUTE OF DEMOGRAPHY}

\section{Working Papers}

Winkler-Dworak, Maria and Laurent Toulemon, Gender Differences in the Transition to Adulthood in France: Is There Convergence Over the Recent Period? VID Working Paper 01/2007.

Prskawetz, Alexia, Marija Mamolo, and Henriette Engelhardt, Reconsidering the Relation between Fertility and Key Fertility-Related Demographic Behaviour across Space and Time, VID Working Paper 09/2006.

Mamolo, Marija, Union Formation, Marriage and First Birth: Convergence Across Cohorts in Austria, Hungary, Northern Italy and Slovenia? VID Working Paper 08/2006.

Goujon, Anne and Samir K.C., Past and Future of Human Capital in Southeast Asia: From 1970 to 2030, VID Working Paper 07/2006.

Lyngstad, Torkild H., Does Community Context have Important Bearings on the Divorce Rate? VID Working Paper 06/2006.

Winkler-Dworak, Maria, The Low Mortality of a Learned Society, VID Working Paper 05/2006.

Kim, Jungho and Alexia Prskawetz, External Shocks, Household Consumption and Fertility in Indonesia, VID Working Paper 04/2006.

Schwarz, Franz, Behavioral Explanation for Educational Health and Mortality Differentials in Austria, VID Working Paper 03/2006.

Schwarz, Franz, The Contributions of Diseases to Increasing Educational Mortality Differential in Austria, VID Working Paper 02/2006.

Goujon, Anne, Vegard Skirbekk, Katrin Fliegenschnee and Pawel Strzelecki, New Times, Old Beliefs: Projecting the Future Size of Religions in Austria, VID Working Paper 01/2006.

Ediev, Dalkhat M., Extension of Fisher's Classical Result on Exponential Dynamics of the Reproductive Value to a Wide Class of Populations, VID Working Paper $10 / 2005$.

Ediev, Dalkhat M., Long-Term Effects of Childbearing Postponement, VID Working Paper 09/2005.

The Vienna Institute of Demography Working Paper Series receives only limited review. Views or opinions expressed herein are entirely those of the authors. 